\title{
Harpin-induced expression and transgenic overexpression of the phloem protein gene AtPP2-A1 in Arabidopsis repress phloem feeding of the green peach aphid Myzus persicae
}

Chunling Zhang ${ }^{1+}$, Haojie Shi ${ }^{1+}$, Lei Chen ${ }^{1,2+}$, Xiaomeng Wang ${ }^{1 \dagger}$, Beibei Lü ${ }^{1}$, Shuping Zhang ${ }^{1}$, Yuan Liang ${ }^{1}$, Ruoxue Liu', Jun Qian', Weiwei Sun', Zhenzhen You', Hansong Dong ${ }^{1 *}$

\begin{abstract}
Background: Treatment of plants with $\mathrm{HrpN}_{\text {Ear }}$ a protein of harpin group produced by Gram-negative plant pathogenic bacteria, induces plant resistance to insect herbivores, including the green peach aphid Myzus persicae, a generalist phloem-feeding insect. Under attacks by phloem-feeding insects, plants defend themselves using the phloem-based defense mechanism, which is supposed to involve the phloem protein 2 (PP2), one of the most abundant proteins in the phloem sap. The purpose of this study was to obtain genetic evidence for the function of the Arabidopsis thaliana (Arabidopsis) PP2-encoding gene AtPP2-A1 in resistance to M. persicae when the plant was treated with $\mathrm{HrpN}_{\mathrm{Ea}}$ and after the plant was transformed with AtPP2-A1.
\end{abstract}

Results: The electrical penetration graph technique was used to visualize the phloem-feeding activities of apterous agamic M. persicae females on leaves of Arabidopsis plants treated with $\mathrm{HrpN}_{\text {Ea }}$ and an inactive protein control, respectively. A repression of phloem feeding was induced by $\operatorname{HrpN}_{\mathrm{Ea}}$ in wild-type (WT) Arabidopsis but not in atpp2-a1/E/142, the plant mutant that had a defect in the AtPP2-A1 gene, the most HrpN $\mathrm{Ea}_{\text {-responsive of } 30 \text { AtPP2 }}$ genes. In WT rather than atpp2-a1/E/142, the deterrent effect of $\mathrm{HrpN}_{\text {Ea }}$ treatment on the phloem-feeding activity accompanied an enhancement of AtPP2-A1 expression. In PP2OETAt (AtPP2-A1-overexpression transgenic Arabidopsis thaliana) plants, abundant amounts of the AtPP2-A1 gene transcript were detected in different organs, including leaves, stems, calyces, and petals. All these organs had a deterrent effect on the phloem-feeding activity compared with the same organs of the transgenic control plant. When a large-scale aphid population was monitored for 24 hours, there was a significant decrease in the number of aphids that colonized leaves of $\mathrm{HrpN}_{\mathrm{Ea}^{-}}$ treated WT and PP2OETAt plants, respectively, compared with control plants.

Conclusions: The repression in phloem-feeding activities of $M$. persicae as a result of AtPP2-A1 overexpression, and as a deterrent effect of $\mathrm{HrpN}_{\mathrm{Ea}}$ treatment in WT Arabidopsis rather than the atpp2-a1/E/142 mutant suggest that AtPP2-A1 plays a role in plant resistance to the insect, particularly at the phloem-feeding stage. The accompanied change of aphid population in leaf colonies suggests that the function of AtPP2-A1 is related to colonization of the plant.

\footnotetext{
* Correspondence: hsdong@njau.edu.cn

† Contributed equally

${ }^{1}$ Key Laboratory of Monitoring and Management of Crop Pathogens and Insect Pests, Ministry of Agriculture of R. P. China, Nanjing Agricultural

University, Nanjing, 210095, PR China

Full list of author information is available at the end of the article
} 


\section{Background}

Harpins are multifunctional proteins produced by Gram-negative plant pathogenic bacteria [1,2]. The firstcharacterized [1] and well-studied harpin [2-7], HrpN $\mathrm{Ea}_{\mathrm{Ea}}$, is secreted by Erwinia amylovora, the bacterial pathogen that causes fire blight disease in rosaceous plants [1]. Multiple functions of harpin proteins, especially in eliciting plant defense responses, were also elucidated initially by studies using $\mathrm{HrpN}_{\mathrm{Ea}}$ as a paradigm [1-3]. Early studies demonstrated that the external application of $\mathrm{HrpN}_{\mathrm{Ea}}$ was able to induce resistance in a variety of plant species [3-7], and that the induced resistance effectively protected plants from attacks by insect herbivores [2,7-9]. $\mathrm{HrpN}_{\mathrm{Ea}}$-induced resistance to insects first was suggested based on observations of field-grown peppers. Plants that had been treated with $\mathrm{HrpN}_{\mathrm{Ea}}$ incurred fewer injuries from the European corn borer than comparable untreated plants [2]. A deterrent effect on striped cucumber beetles was observed in $\mathrm{HrpN}_{\mathrm{Ea}}$-treated cucumber; striped cucumber beetles preferred to colonize untreated control plants rather than $\mathrm{HrpN}_{\mathrm{Ea}}$-treated plants [8]. $\mathrm{HrpN}_{\mathrm{Ea}}$-induced resistance was also effective in impeding infestations of aphids, an important type of phloem-feeding herbivores $[9,10]$. In cucumbers grown under environmentally controlled conditions, $\mathrm{HrpN}_{\mathrm{Ea}}$ treatment had a deterrent effect on colonization by the muskmelon aphid Aphis gossypii (Glover), which preferred to colonize control plants rather than $\mathrm{HrpN}_{\mathrm{Ea}}$-treated plants [9]. In Arabidopsis thaliana (Arabidopsis), moreover, $\mathrm{HrpN}_{\mathrm{Ea}^{-}}$ induced resistance was shown to repress infestation of the green peach aphid Myzus persicae (Sulzer), a generalist phloem-feeding insect [10].

Phloem-feeding insects are highly specialized in their mode of feeding [11] and present a unique stress on plant fitness [12-15]. These insects use their slender stylets to feed from a single-cell type, the phloem sieve element $[8,16]$. The feeding process can be monitored by the electrical penetration graph (EPG) technique [16]. Pivotally, a stylet puncturing of the host plant cell, shown as a probe in the EPG, may lead to uptake of the phloem sap. In order to prevent protein clogging inside the sieve element, ejection of watery saliva is essential in feeding from the phloem $[13,16]$. This ejection is detected in the EPG as E1 salivation and always precedes phloem sap ingestion [16]. During ingestion from the sieve element, the watery E2 salivation occurs, and this E2 saliva is added to the ingested sap, thought to prevent phloem proteins from clogging inside the capillary food canal [16]. Therefore, salivation is a crucial event during the phloem-feeding process for insects to overcome a number of phloem-related plant properties and reactions [13-19].

In response to the phloem-feeding stress, plants defend themselves specifically using the phloem-based defense (PBD) mechanism [14-16], which can be also activated by other cues, such as wounding [20-22], besides insect attacks [14,20-22]. Proposed components of PBD include the phloem protein 1 (PP1) and phloem protein 2 (PP2), which represent a type of the most abundant proteins in the phloem sap [23]. PP2 is a phloem lectin conserved in plants $[23,24]$ and is believed to play a role in the establishment of PBD induced by insect attacks $[21,25,26]$ and other stresses, such as wounding $[16,21,22,26]$ and oxidative conditions [25]. In pumpkin, PP1 monomers and PP2 dimers are covalently cross-linked via disulphide bonds, forming high molecular weight polymers that close the sieve pores $[21,25,26]$. This response is induced by oxidative stress [25] but normally accompanies the synthesis of the $\beta-1,3$-glucan callose by callose synthase [20] that accumulates on sieve plates after different stress treatments [21]. Phloem protein plugging and callose closure of sieve pores, and callose coagulation on sieve plates as well, is hypothesized to serve as a physical barrier to prevent the insect from phloem-feeding activity [26]. Nevertheless, evidence for the function of phloem proteins in insect defense has been in paucity.

In the completely sequenced Arabidopsis genome, PP2 (previously PP2-like) genes were identified as a large multigene family constituted of 30 members [23,27], AtPP2-A1 to AtPP2A-15 and AtPP2-B1 to AtPP2-B15 [23]. To our knowledge, however, little has been known about bioprocesses affected by these genes and properties of the encoded proteins. Although Arabidopsis mutants that represent multiple mutation alleles of AtPP2 have been generated [27,28], subsequent biological effects have not been studied, and especially, effects of AtPP2 mutations on the plant resistance to insects are unclear. For example, different types of Arabidopsis mutants were generated by T-DNA insertion at distinct locations in the AtPP2-A1 DNA sequence; atpp $2-a 1 / \mathrm{P} /-210$ resulted from the insertion at nucleotide residue -210 in the promoter region. When grown on an artificial medium, the atpp $2-a 1 / \mathrm{P} /-210$ mutant performs as the wild-type (WT) plant in response to infestations of $M$. persicae adults and newborn nymphs in 24 hours after colonization by the adults [29]. There is as yet no evidence to show if atpp $2-a 1 / \mathrm{P} /-210$ impacts longer behaviors and feeding activities of the insect and if other mutation alleles of AtPP2-A1 have biological effects $[27,28]$.

The purpose of this study was to obtain genetic evidence that could elucidate a function of AtPP2-A1 in Arabidopsis resistance to $M$. persicae. We began with determining the effect of AtPP2-A1 on phloem feeding of aphids that colonized the plants treated with $\mathrm{HrpN}_{\mathrm{Ea}}$ according to previous evidence that the $\mathrm{HrpN}_{\mathrm{Ea}}$ treatment and $M$. persicae infestation had some degrees of 
overlapping effects on the induction of plant responses. For example, formation of the PP2-PP1 complex needs reactive oxygen burst in cucurbit [25] while reactive oxygen burst is a conserved response in Arabidopsis treated with any harpins [30,31]. M. persicae infestation induces an elevation of the ethylene level [32] and triggers modest induction of ethylene-dependent responses $[32,33]$, whereas, $\mathrm{HrpN}_{\mathrm{Ea}}$ induces resistance to $M$. persicae by activating the ethylene-signaling pathway [4,34]. Therefore, we devised to determine the possibility that $\mathrm{HrpN}_{\mathrm{Ea}}$-induced resistance involves the PBD mechanism to encounter with $M$. persicae infestation. In order to further test this hypothesis, we generated AtPP2-A1overexpression plants and investigated them to elucidate the supposed function of AtPP2-A1. In this article, we report evidence that harpin-induced expression and transgenic overexpression of AtPP2-A1 induce a repression in the phloem-feeding activity of $M$. persicae.

\section{Results}

\section{$\mathrm{HrpN}_{\mathrm{Ea}}$ treatment in Arabidopsis induces a repression in} phloem feeding and colonization by $M$. persicae

The $\mathrm{HrpN}_{\mathrm{Ea}}$ protein used in this study was produced by prokaryotic expression with a vector that carried a $h r p N_{E a}$ gene insert; the $h r p N_{E a}$-absent Empty Vector Preparation (EVP) that contained inactive proteins but not $\mathrm{HrpN}_{\mathrm{Ea}}$ was used as a control [6]. We investigated activities of $M$. persicae feeding from Arabidopsis (ecotype Col-0) WT plants following treatment with EVP and $\mathrm{HrpN}_{\mathrm{Ea}}$, respectively. Because a period of five days is usually required for the induction of plant defense responses [3-8], plants at the fifth day posttreatment (dpt) were artificially colonized with uniform ten-dayold apterous (wingless) agamic $M$. persicae females transferred from an Arabidopsis nursery. Aphid feeding activities were studied by the EPG technique applied to 20 aphids that colonized leaves of Arabidopsis plants treated with EVP and $\operatorname{HrpN}_{\mathrm{Ea}}$, respectively. Feeding activities were depicted as different waveform patterns recognized according to the standard previously established [35] and widely used [13,16,17,36]. Based on the EPG patterns, all the 20 aphids tested in five repetitions of the experiments for each treatment accomplished major steps of the feeding process, but aphid activities varied greatly depending on feeding stages (Table 1).

Figure 1a shows a four-hour EPG record of aphid feeding from the WT plant. The nonpuncturing phase (Figure 1a, np) indicated the stylet staying outside the cuticle. Cell puncturing (Figure 1a, probe) led to the pathway phase (Figure 1a, path) in which the stylet penetrated between cells en route to the vascular tissue [35]. In the four-hour EPG record, total number and duration of the nonpuncturing phase, time to the first cell puncturing or the first pathway phase, and total number and duration of the pathway phase were all similar in $\mathrm{HrpN}_{\mathrm{Ea}}$-treated plants as in control plants (Table 1). The pathway phase represents insect's efforts in navigating the phloem and preparing to ingest sap from sieve elements $[16,17]$. Subsequently, aphids may proceed to the phloem phase (Figure 1a, PP) in which ingestion of the phloem sap may occur [16]. The pathway phase may be also connected with the xylem phase, indicating stylet penetration of the xylem in the vascular tissue [16], but xylem phase was not found in this study. Analyses of the four-hour EPG record as a whole suggested that the plant treatment with $\mathrm{HrpN}_{\mathrm{Ea}}$ did not evidently change aphid activities outside vascular tissues when evaluated in a four-hour course of surveys (Table 1). However, analyses by hour offered additional information. In the first hour, especially, the nonpuncturing phase was more frequent with longer duration while the pathway phase was more but shorter under the $\mathrm{HrpN}_{\mathrm{Ea}}$ treatment condition compared with control. This result suggested that the $\mathrm{HrpN}_{\mathrm{Ea}}$ treatment impeded aphids in early feeding activities, both puncturing of the plant cell and navigating of the phloem. Subsequently, however, the phloem phase was always shorter, in $\mathrm{HrpN}_{\mathrm{Ea}}$-treated plants than in control plants, no matter if the EPG patterns were analyzed by hour or based on the four-hour record as a whole (Table 1).

Based on the four-hour EPG record, the proportions of times within the pathway phase and time to the first phloem phase were much longer, suggesting the impediment to aphids in locating the ingestion site within the vascular tissue, in $\mathrm{HrpN}_{\mathrm{Ea}}$-treated plants compared with control plants (Figure 1a; Table 1). On HrpN $\mathrm{Ea}_{\mathrm{E}}$-treated plants, moreover, aphids took fewer actions to puncture cells (Table 1, Number of cell puncturing) and to enter the phloem phase (Table 1, Number of phloem phase) after the first entry of phloem phase. These results suggested that phloem properties of $\mathrm{HrpN}_{\mathrm{Ea}}$-treated plants were changed as unfavourable to aphid feeding. In consistence with this notion, total duration of the phloem phase was markedly shorter in $\mathrm{HrpN}_{\mathrm{Ea}}$-treated plants than in control plants (Table 1). Noticeably, duration of the phloem phase in the second hour of the EPG monitoring, being 30 in $\mathrm{HrpN}_{\mathrm{Ea}^{-}}$ treated plants and $14 \mathrm{~min}$ in control plants, on average, strongly suggested the deterrent effect of the $\mathrm{HrpN}_{\mathrm{Ea}}$ treatment on the phloem-feeding activity of $M$. persicae.

In the phloem phase, E1 and E2 salivations were recognized by dissecting the EPG waveform patters (Figure 1b). Compounds of E1 and E2 saliva produced by aphids after stylet entry of the phloem are believed to function in preventing protein clogging inside the sieve element and preventing phloem proteins from clogging inside the capillary food canal, respectively [16]. Thus, E1 and E2 salivations play an important role in ingestion of the phloem sap by the insects $[13,16]$. As shown in Table 1, durations of both 
Table 1 Four-hour electrical penetration graph (EPG) analyses of the green peach aphid Myzus persicae feeding from wild-type (WT) Arabidopsis plants

\begin{tabular}{|c|c|c|c|c|}
\hline Activity examined & & $\begin{array}{l}\text { Control group mean } \\
\text { (SD*) }\end{array}$ & $\begin{array}{l}\mathrm{HrpN}_{\mathrm{Ea}} \text { treatment group mean } \\
\left(\mathrm{SD}^{*}\right)\end{array}$ & $\begin{array}{l}\text { Student's } t \text {-test }(\mathrm{n}= \\
\text { 20) }\end{array}$ \\
\hline \multirow[t]{5}{*}{ Number of nonpuncturing phase } & total & $13.5(2.2)$ & $16.0(3.5)$ & ** \\
\hline & 1 st $h$ & $6.0(1.0)$ & $13(2.5)$ & $p<0.01$ \\
\hline & 2nd h & 0 & 0 & \\
\hline & $3 r d h$ & $6.5(0.8)$ & $2(0.5)$ & $p<0.01$ \\
\hline & 4th $\mathrm{h}$ & $1.0(0.3)$ & $1.0(0.3)$ & ** \\
\hline \multirow[t]{5}{*}{ Duration of nonpuncturing, min } & total & $19.8(5.2)$ & $16.8(4.6)$ & ** \\
\hline & $1 \mathrm{st} h$ & $4.9(0.3)$ & $15.0(3.9)$ & $p<0.01$ \\
\hline & 2nd h & 0 & 0 & \\
\hline & $3 r d h$ & $11.1(3.6)$ & $1.3(0.4)$ & $p<0.01$ \\
\hline & 4th $\mathrm{h}$ & $3.8(1.2)$ & $0.5(0.2)$ & $p<0.01$ \\
\hline Time to 1 st cell puncturing, min & & $2.1(0.6)$ & $2.1(0.3)$ & ** \\
\hline Time to 1st pathway, min & & $3.3(0.5)$ & $3.0(0.4)$ & ** \\
\hline \multirow[t]{5}{*}{ Number of pathway phase } & total & $19.5(2.0)$ & $16.5(1.5)$ & ** \\
\hline & $1 s t h$ & $5.2(0.5)$ & $11.5(1.0)$ & $p<0.01$ \\
\hline & 2nd $\mathrm{h}$ & $3.0(0.3)$ & $2.0(0.1)$ & ** \\
\hline & $3 r d h$ & $7.3(1.0)$ & $2.0(0)$ & $p<0.01$ \\
\hline & 4th $\mathrm{h}$ & $4.0(0.5)$ & $2.0(0.2)$ & $p<0.01$ \\
\hline \multirow[t]{5}{*}{ Duration of pathway phase, min } & total & $175.7(48.9)$ & $205.0(62.5)$ & $p<0.01$ \\
\hline & $1 s t h$ & $55.1(6.7)$ & $45.0(7.5)$ & $p<0.01$ \\
\hline & 2nd h & $37.2(3.5)$ & $43.9(7.2)$ & $p<0.05$ \\
\hline & $3 r d h$ & $47.4(5.6)$ & $56.6(8.0)$ & $p<0.01$ \\
\hline & 4th $\mathrm{h}$ & $36 / 0(3.2)$ & $59.5(10.5)$ & $p<0.01$ \\
\hline Time to $1 \mathrm{st}$ phloem phase, min & & $85.6(10.7)$ & $104.3(12.0)$ & $p<0.01$ \\
\hline $\begin{array}{l}\text { Number of cell puncturing after 1st phloem } \\
\text { phase }\end{array}$ & & $20.5(2.0)$ & $11(1.6)$ & $p<0.01$ \\
\hline \multirow[t]{5}{*}{ Number of phloem phase } & total & $7(1.0)$ & $3.0(0.2)$ & $p<0.01$ \\
\hline & $1 s t h$ & 0 & 0 & \\
\hline & 2nd h & $3.0(0.5)$ & $1.5(0.5)$ & $p<0.01$ \\
\hline & $3 r d h$ & $1.0(0)$ & $1.5(0.5)$ & ** \\
\hline & 4th $\mathrm{h}$ & $3.0(0.5)$ & 0 & $p<0.01$ \\
\hline \multirow[t]{5}{*}{ Duration of phloem phase, min } & total & $44.5(8.5)$ & $18.2(3.6)$ & $p<0.01$ \\
\hline & $1 \mathrm{st} h$ & 0 & 0 & \\
\hline & 2nd h & $22.8(5.0)$ & $16.1(3.5)$ & $p<0.01$ \\
\hline & $3 r d h$ & $1.5(0.5)$ & $2.1(0.6)$ & $p<0.01$ \\
\hline & 4th $\mathrm{h}$ & $20.2(3.5)$ & 0 & $p<0.01$ \\
\hline \multirow[t]{3}{*}{ Duration of phloem feeding, min } & total & $44.5(8.5)$ & $18.2(3.6)$ & $p<0.01$ \\
\hline & E1 & $12.6(2.8)$ & $5.0(1.4)$ & $p<0.01$ \\
\hline & E2 & 31.9 (3.5) & $13.2(3.1)$ & $p<0.01$ \\
\hline
\end{tabular}

*SD, standard deviation. ${ }^{* *}$ Insignificant difference at $p<0.05$.

E1 and E2 salivations were much shorter in $\mathrm{HrpN}_{\mathrm{Ea}}$-treated plants than control plants, confirming the deterrent effect of the $\mathrm{HrpN}_{\mathrm{Ea}}$ treatment on the phloem-feeding activity of $M$. persicae.

To correlate repression in the phloem-feeding activity with colonization of Arabidopsis by M. persicae, we monitored a large-scale population of the insect and surveyed a 24-hour fluctuation in leaf colonies. A total of 1,200 uniform individuals of apterous and agamic $M$. persicae females were monitored in four repetitions of the experiments for plants treated with EVP and $\mathrm{HrpN}_{\mathrm{Ea}}$, respectively. The number of aphids that stayed in their colonies on leaves was counted and the number of aphids that run away from the leaf colonies was calculated at intervals in 


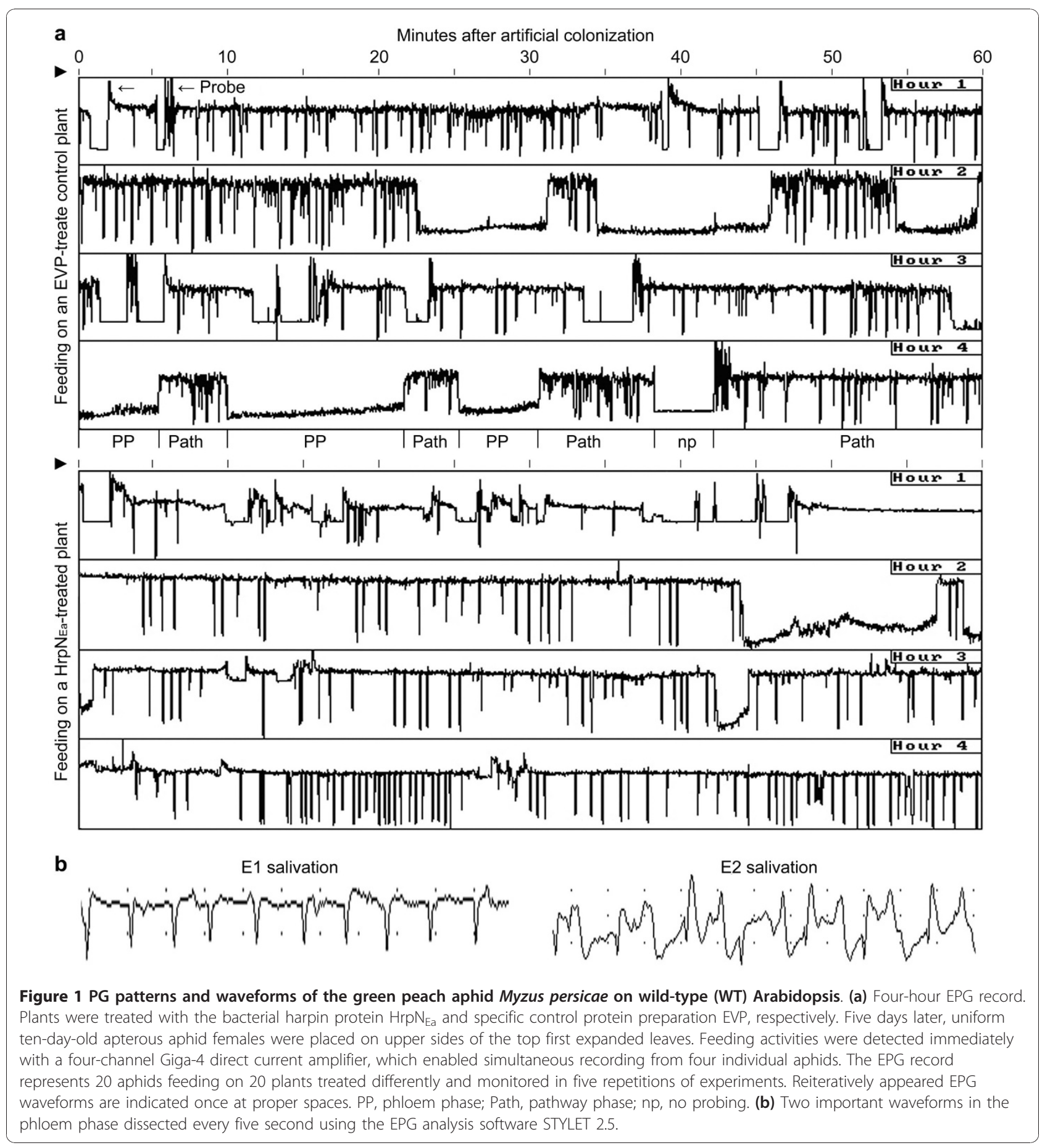

24 hours (Figure 2). At each time point, the number of aphid individuals run away from their colonies on leaves of $\mathrm{HrpN}_{\mathrm{Ea}}$-treated plants was greater than the number of the insect run away from colonies on leaves of control plants (Student's t-test, $P<0.01)$. Proportions of aphids escaped from leaf colonies in control plants were close at the different intervals, but much higher proportions of aphid escapes from leaf colonies in $\mathrm{HrpN}_{\mathrm{Ea}}$-treated plants were observed in the short period of two to four hours. And this period was critical to the effect of $\mathrm{HrpN}_{\mathrm{Ea}}$ treatment on colonization of the plant, consistent with the effect on the phloem-feeding activity (Figure 1a). In 24 hours, a total of $74.8 \%$ aphids on average run away from their colonies on leaves of $\mathrm{HrpN}_{\mathrm{Ea}}$-treated plants, in contrast to totally $17.7 \%$ aphids escaped from leaf colonies in control plants (Figure 2; Student's t-test, $P<0.01$ ). In subsequent 

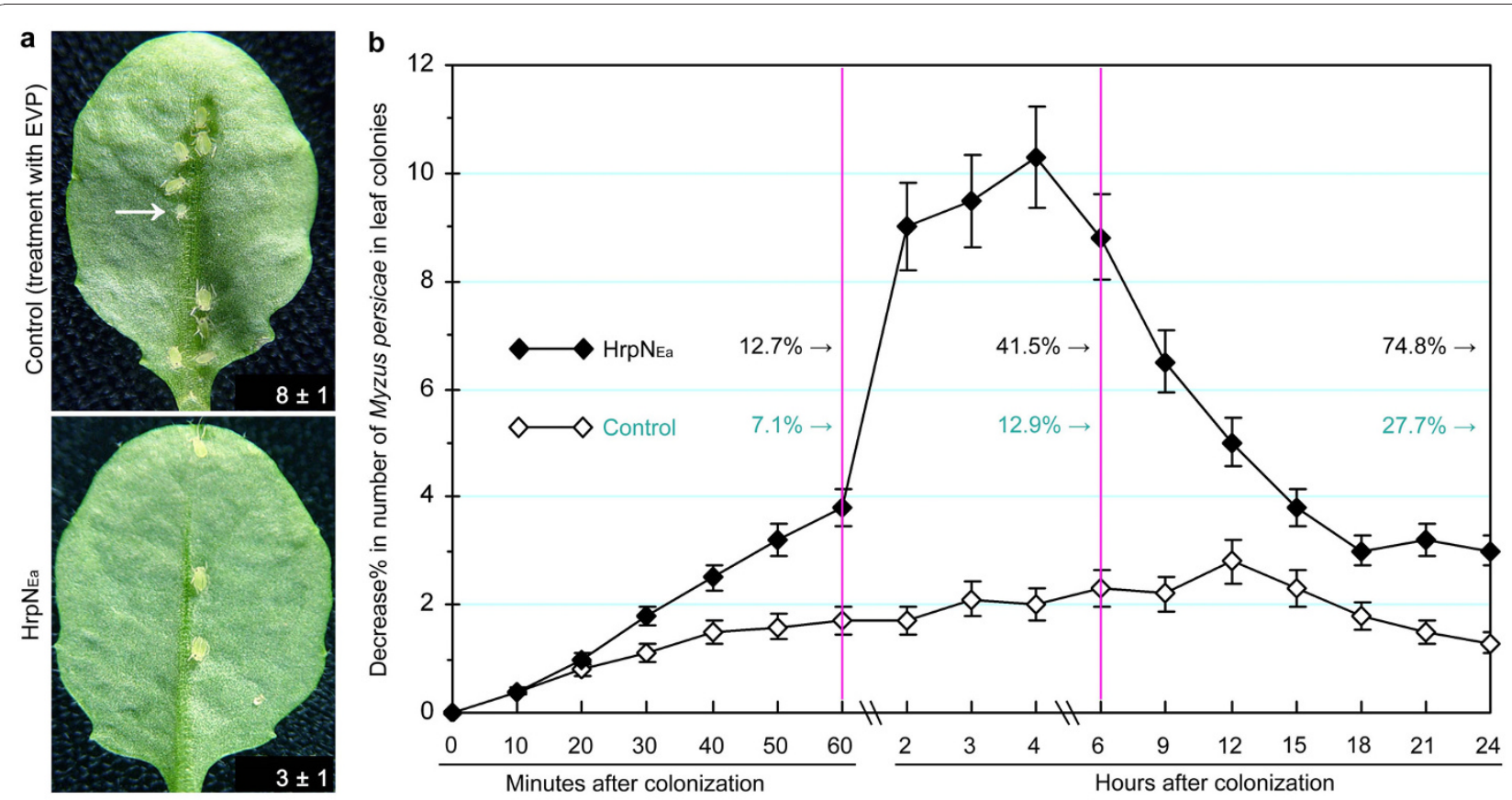

Figure 2 24-hour monitoring of $\boldsymbol{M}$. persicae population in leaf colonies. (a) Appearance of aphid colonies on leaves. WT plants were treated with $\mathrm{HrpN}_{\mathrm{Ea}}$ and EVP, respectively. Five days later, uniform aphids were placed on lower sides of the top two expanded leaves, 10 aphids/leaf; leaves were photographed 24 hours later. The arrowhead points a nymph produced after leaf colonization. The numerical values, given as mean \pm standard deviation (SD), indicate the number of aphids that stayed on the leaf colony for 24 hours. A photo represents 120 leaf colonies on 60 plants. (b) Changes of aphid population in 24 hours. Leaf colonies on plants from (a) were surveyed, the number of aphids that stayed in a leaf colony was scored, and percent decrease in the number of aphids that left the leaf colonies was calculated as mean \pm standard deviation (SD) of replicate results ( $n=120$ leaf colonies). The numerical values indicate total proportions (means \pm SDs) of decreases in aphid populations within 1,6 and 24 hpt (hour posttreatment).

days, aphids that had run away from the original leaf colonies were found in a drifting status, died, and appeared as white carcases on other different parts of the plants. These observations indicate that the $\mathrm{HrpN}_{\mathrm{Ea}}$ treatment impairs the stability of Arabidopsis colonization by M. persicae.

\section{Arabidopsis atpp2-a1/E/142 mutant pampers M. persicae in phloem feeding}

To gain information about relationships between previously identified 30 AtPP2 genes [23] and $\mathrm{HrpN}_{\mathrm{Ea}}$-induced repression in the phloem-feeding activity of $M$. persicae, we studied expression of these genes in $\mathrm{HrpN}_{\mathrm{Ea}}$-treated WT Arabidopsis plants. Reverse transcriptase-polymerase chain reaction (RT-PCR) was performed using the $E F 1 \alpha$ gene as a reference [6,37] to detect the expression of 15 AtPP2-A genes and $15 A t P P 2-B$ genes [23]. As shown in Figure 3a, transcript levels of the genes, except AtPP2-A1 and AtPP2$A 14$, in $\mathrm{HrpN}_{\mathrm{Ea}}$-treated plants were similar when tested at the 24th hour posttreatment (hpt) as tested at $0 \mathrm{hpt}$ (immediately after the plant treatment). However, both AtPP2-A1 and AtPP2-A14 were expressed at enhanced extents in $\mathrm{HrpN}_{\mathrm{Ea}}$-treated plants. Subsequent real-time RT-PCR analyses using the EF1 $\alpha$ and Actin 2 genes as references $[37,38]$ revealed a greater expression level of
AtPP2-A1 than AtPP2-A14. Relatively, AtPP2-A1 and AtPP2-A14 transcripts accumulated in 24 hours were 5 and 2 times more, respectively, in $\mathrm{HrpN}_{\mathrm{Ea}}$-treated plants than in control plants (Figure $3 \mathrm{~b}$ ).

To correlate the role of $\mathrm{HrpN}_{\mathrm{Ea}}$ in enhancing gene expression with the role in repressing phloem feeding of $M$. persicae, we investigated Arabidopsis mutants previously generated by T-DNA insertion at AtPP2- $A$ sequences. Two AtPP2-A1 sequence-indexed lines were chosen for the test because the AtPP2-A1 protein had been shown to affect weight gain in $M$. persicae nymphs [24], and the other eight AtPP2-A-modified mutants were considered for comparison because the $A t P P 2-A$ genes differed from $A t P P 2-A 1$ in response to $\mathrm{HrpN}_{\mathrm{Ea}}$ (Figure $3 \mathrm{a}$ ). The ten mutants were confirmed for the presence of T-DNA insert according to available information (Table 2); they were named conventionally after lowercase gene symbols, suffixed with the insert locations, including gene DNA components ( $\mathrm{P}$, promoter; $\mathrm{E}$, exon; I, intron) and nucleotide residue sites at the gene DNA sequences. Mutants were compared with WT in expression of the corresponding genes and aphid behaviors on leaf colonies.

Parallel RT-PCR analyses of RNA samples isolated at 0 and $24 \mathrm{hpt}$ revealed that the AtPP2-A genes performed 


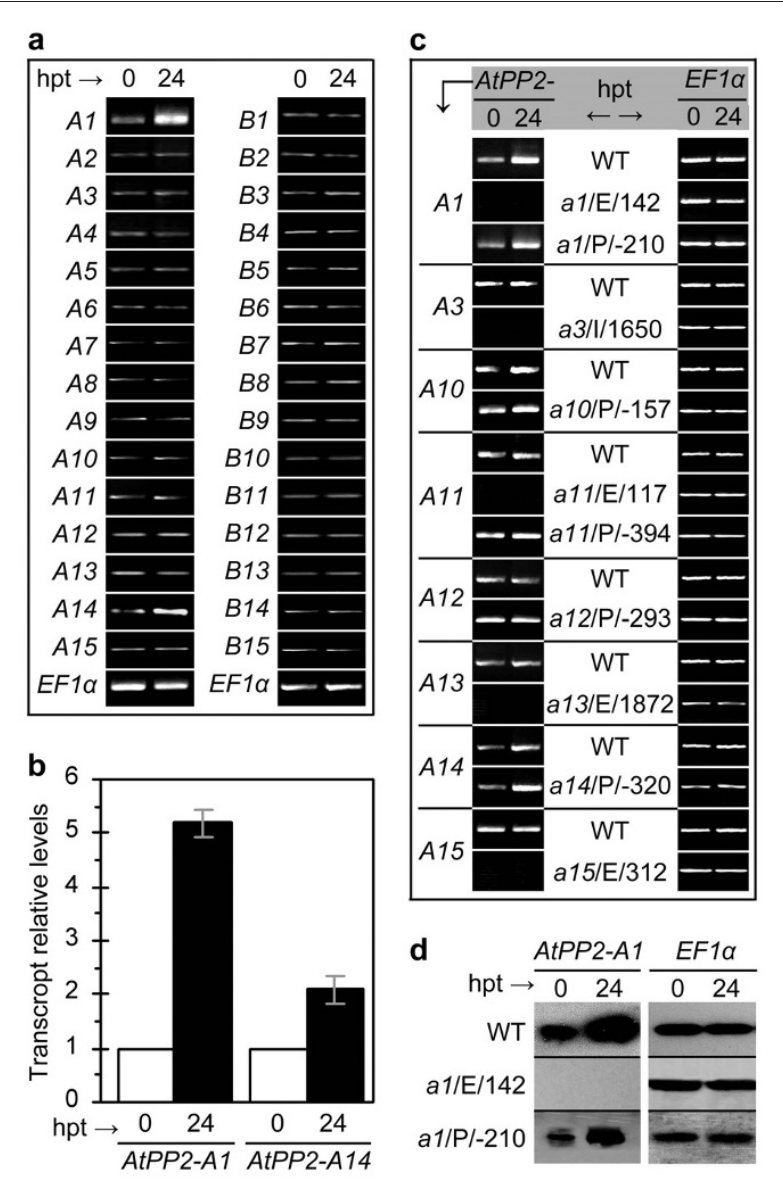

Figure 3 Analyses of AtPP2 gene expression. (a-d) Plants were treated with $\mathrm{HrpN}_{\mathrm{Ea}}$ and sampled at 0 hpt (immediately after treatment) and 24 hpt. Gene expression was determined by Reverse transcriptase-polymerase chain reaction (RT-PCR) using EF1 $\alpha$ as a reference gene, by real-time RT-PCR using EF1 $\alpha$ and ACTIN2 genes as references, or by northern blot hybridization with specific probes. (a) RT-PCR analyses of gene expression in WT plants. AtPP2-A1 through AtPP2-A15 and AtPP2-B1 through AtPP2-B15 are abbreviated as A1 through $A 15$ and $B 1$ through $B 15$, respectively. (b) Real-time RT-PCR analysis of AtPP2-A1 and AtPP2-A14 expression in WT plants. Gene transcript was quantified as mean $\pm \mathrm{SD}$ ( $n=4$ repeats) relative to reference genes and normalized to null-template controls. (c) RT-PCR analyses to determine effects of the WT plant and AtPP2-A-modified mutants on expression of selected AtPP2-A genes. The sequenceindexed T-DNA insertion mutants are shown as ellipsis of prefixal atpp2-. (d) Northern blots hybridized with probes specific to AtPP2-A1 or EF1 $\alpha$. Both mutants are shown in abbreviated form.

differently in corresponding mutants compared with the WT plant (Figure 3c). Both the basal expression (0 hpt) and $\mathrm{HrpN} \mathrm{N}_{\mathrm{Ea}}$-induced expression (24 hpt) of AtPP2-A1 was detected in the atpp $2-a 1 / \mathrm{P} /-210$ mutant as in WT but not in the atpp2-a1/E/142 mutant (Figure 3c). This result was confirmed by northern blot hybridization (Figure 3d). And this result conformed to the PLACE Web Signal Scan [39], which revealed 37 types of cis-acting regulatory DNA elements present in the predicted 344-bp promoter of AtPP2-A1. Eighteen elements exist as a single copy and 19 elements have multiple copies, located at distant 83 sites in the promoter sequence. However, none of the elements was disrupted by T-DNA insertion and this might account for AtPP2-A1 expression in atpp2-a1/P/-210. Similarly, none of 35 types of cis-acting regulatory DNA elements scanned in the upstream -370 region of the AtPP2-A14 DNA sequence was disrupted in atpp $2-a 14 / \mathrm{P} /-320$. This mutant performed as WT in both the basal expression and $\mathrm{HrpN}_{\mathrm{Ea}}$-induced expression of AtPP2-A14 (Figure 3c). The other eight mutants behaved differently in expression of the corresponding AtPP2-A genes. AtPP2-A3, -A11, -A13, and $-A 15$ were not expressed in their corresponding mutants atpp2-a3/I/ 1650, $-a 11 / \mathrm{E} / 177,-a 13 / \mathrm{E} / 1872$, and $-a 15 / \mathrm{E} / 312$. In contrast, atpp2-a10/P/-157, a11/P/-394, a12/P/-293, a14/ $\mathrm{P} /-320$ performed as WT in the expression of the corresponding AtPP2-A genes. In atpp2-a12/P/-293 and atpp2a12/P/-293, T-DNA insert did not disrupt any DNA regulatory motifs present in AtPP2-A11 and AtPP2-A12 promoters. In atpp $2-a 10 / \mathrm{P} /-157, \mathrm{~T}-\mathrm{DNA}$ insert disrupted the pollen-specific transcription activator element AGAAA (\#S000245) [40,41] located between -159 and -155 in the AtPP2-A10 sequence. In atpp2-a11/P/-394, the MYB recognition site TGGTTT (\#S000408) [42] located between -398 and -393 in the AtPP2-A11 sequence was disjoined by T-DNA insertion. However, both mutations did not affect basal expression of the genes (Figure 3c). In the ten mutants, therefore, only atpp 2-a1/E/142 represents an effective mutation allele, which may be responsible for a transcriptional stop of $A t P P 2-A 1$ in the plant and result in experimental compromises in both the basal expression and $\mathrm{HrpN}_{\mathrm{Ea}}$-induced expression of the gene.

The ten AtPP2-A-modified mutants were compared with the WT plant in terms of colonization and feeding by aphids. Based on monitoring of large-scale populations of apterous and agamic $M$. persicae females $(1,200$ aphids/treatment/plant genotype), the insect colonies on leaves of atpp2-a1/E/142 were stable, shown as a smaller rate of the population decrease in 24 hours, than those on WT and the other nine mutants (Figure 4a; ANOVA test, $p<0.01)$. In atpp $2-a 1 / \mathrm{E} / 142$, the deterrent effect of $\mathrm{HrpN}_{\mathrm{Ea}}$ on colonization by the insect was little, but the effect was evident in the other mutants as in WT (Figure 4a). Based on the four-hour EPG record, total durations of nonpuncturing and pathway phases had little and insignificant differences between WT and atpp2-a1/E/142 under the same condition, $\operatorname{HrpN}_{\mathrm{Ea}}$ treatment or control (Table 3). Then, the four-hour EPG record of aphid feeding from leaves was analyzed to particularly calculate total duration of the phloem phase (Figure $4 b$ ), which well reflected $\mathrm{HrpN}_{\mathrm{Ea}}$-induced repression in aphid feeding from the WT phloem (Table 1). Apparently, aphids preferred to feed from atpp2-a1/ 
Table 2 Information on AtPP2-A-defected Arabidopsis mutants investigated in this study

\begin{tabular}{|c|c|c|c|c|c|}
\hline $\begin{array}{l}\text { Gene } \\
\text { name }\end{array}$ & Locus no. & Mutant name & $\begin{array}{l}\text { T-DNA } \\
\text { insertion } \\
\text { site }\end{array}$ & $\begin{array}{l}\text { Mutant seed } \\
\text { stock no. }\end{array}$ & TAIR $^{\mathbf{b}}$ annotations \\
\hline AtPP2-A1 & AT4G19840 & atpp2-a1/E/142 & Exon, 142 & CS837256 & $\begin{array}{l}\text { T-DNA insertion lines; a modified approach of thermal asymmetric } \\
\text { interlaced-PCR was used to amplify DNA fragments flanking the T-DNA } \\
\text { left border from the transformed lines; no phenotype information } \\
\text { available at this time. }\end{array}$ \\
\hline AtPP2-A11 & AT1G63090 & atpp2-a1/P/-394 & $\begin{array}{l}\text { Promoter, } \\
-394\end{array}$ & CS842726 & \\
\hline AtPP2-A1 & AT4G19840 & atpp2-a1/P/-210 & $\begin{array}{l}\text { Promoter, } \\
-210\end{array}$ & SALK_080914C & $\begin{array}{l}\text { Sequence-indexed T-DNA insertion lines; presence of the insertion was } \\
\text { analyzed by PCR; kanamycin resistance gene may be silenced; PCR- or } \\
\text { hybridization-based segregation analysis is required to confirm presence } \\
\text { and homozygosity of insertion; may be segregating for phenotypes that } \\
\text { are not linked to the insertion; may have additional insertions potentially } \\
\text { segregating; no phenotype information available at this time. }\end{array}$ \\
\hline AtPP2-A10 & AT1G10155 & atpp2-a10/P/-157 & $\begin{array}{l}\text { Promoter, } \\
-157\end{array}$ & SALK_107807C & \\
\hline AtPP2-A3 & AT2G26820 & atpp2-a3/l/1650 & $\begin{array}{l}\text { Intron, } \\
1650\end{array}$ & SALK_005443C & \\
\hline AtPP2-A11 & AT1G63090 & atpp2-a11/E/117 & Exon, 117 & SALK_080546 & \\
\hline AtPP2-A12 & AT1G12710 & atpp2-a12/P/-293 & $\begin{array}{l}\text { Promoter, } \\
-293\end{array}$ & SALK_015774 & \\
\hline AtPP2-A13 & AT3G61060 & atpp2-a13/E/1872 & Exon, 1872 & SALK_046907 & \\
\hline AtPP2-A14 & AT5G52120 & atpp2-a14/P/-320 & $\begin{array}{l}\text { Promoter, } \\
-320\end{array}$ & SALK_066553 & \\
\hline AtPP2-A15 & AT3G53000 & atpp2-a1/E/312 & Exon, 312 & SALK_022649 & \\
\hline
\end{tabular}

${ }^{\mathrm{a}}$ Distribution seeds of atpp2-a1/P/-210, atpp2-a10/P/-157 and atpp2-a3///1650 are from confirmed lines and T2 or T3 generation for the other mutants.

${ }^{\mathrm{b}} \mathrm{TAIR}$, The Arabidopsis Information Resource http://www.arabidopsis.org databases.

E/142 (Figure 4c). In the mutant, total duration of the phloem phase in 4 hours was much longer than that in the other mutants and WT as well (Figure 4b; Table 3). Both the second and fourth hour of the EPG record indicated significant deterrent effect of the $\mathrm{HrpN}_{\mathrm{Ea}}$ treatment on aphid feeding from the WT phloem (Table $1)$, but the deterrent effect was lost in atpp2-a1/E/142 (Figure 4c; Table 3). Duration of the phloem phase in the second-hour EPG was much shorter in WT plants treated with $\mathrm{HrpN}_{\mathrm{Ea}}$ vs. EVP, but the duration was close in atpp2-a1/E/142 in despite of treatments (Figure 4c; Table 3). These results suggest that atpp2-a1/E/142 pampers $M$. persicae in phloem feeding and that AtPP2$A 1$ plays a role in $\mathrm{HrpN}_{\mathrm{Ea}}$-induced repression of the phloem-feeding activity.

To gain information about the general function of AtPP2-A1 in Arabidopsis resistance to M. persicae, we compared atpp 2-a1/E/142 with the other nine mutants and with WT as well in the effects on multiplication of the insect and subsequent nymph activities. The reproduction rate was scored as the ratio between total numbers of newborn nymphs and total numbers of aphid adults that stayed on leaves in five days after colonization. As shown in Figure 4d, reproduction rates were much smaller under the condition of $\mathrm{HrpN}_{\mathrm{Ea}}$ treatment vs. control (Student's $t$-test, $p<0.01$ ) irrespective of the plant genotypes, suggesting that $\mathrm{HrpN}_{\mathrm{Ea}}$-induced repression of $M$. persicae multiplication [4] was not related to the AtPP2-A1 gene. The gene, however, showed a repressive effect on plant colonization by newborn nymphs. Nymph colonies were more stable on atpp2-a1/E/142 with a smaller proportion of the population decrease than the other mutants or WT (Figure 4e; ANOVA test, $p<0.01)$. In atpp 2-a1/E/142, the deterrent effect of $\mathrm{HrpN}_{\mathrm{Ea}}$ on colonization by nymphs was little, but the effect was evident in the other mutants as in the WT plant (Figure 4e). Evidently, AtPP2-A1 does not affect aphid reproduction, but instead, the gene plays a role in repressing plant colonization by nymphs as by adults.

\section{AtPP2-A1-overexpression confers repressed phloem feeding of $M$. persicae}

The AtPP2-A1 gene was cloned into the binary vector pBI121 under control by the cauliflower mosaic virus $35 \mathrm{~S}$ promoter (35S), creating $p$ BI121::35S::AtPP2-A1 (Figure $5 \mathrm{a})$. Transformation of WT Arabidopsis with the recombinant unit generated PP2OETAt (AtPP2-A1-overexpression transgenic $A$. thaliana) plants. Ten PP2OETAt lines were selected and designated as PP2OETAt1 through PP2OETAt10 according to AtPP2-A1 expression levels 

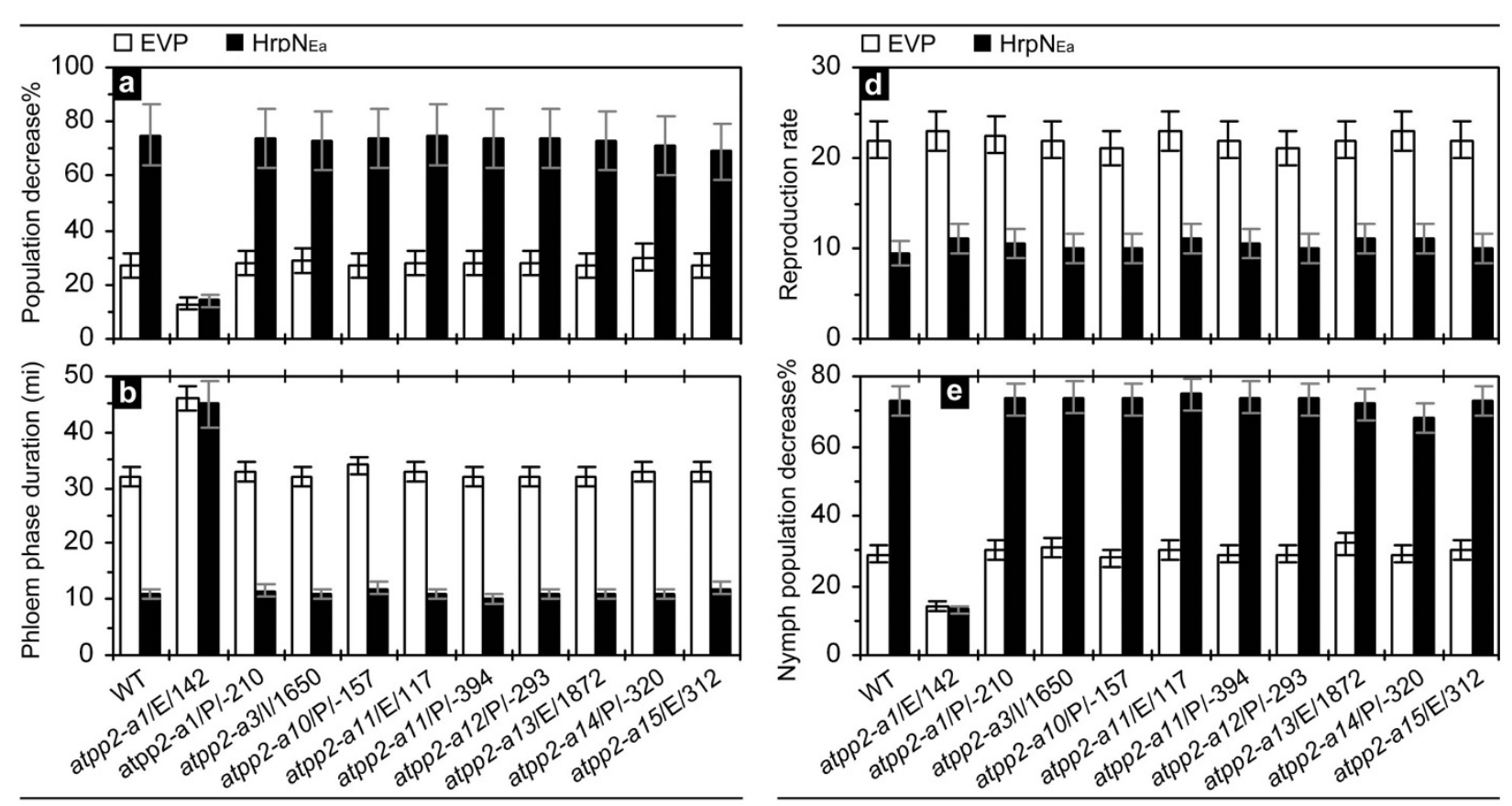

C
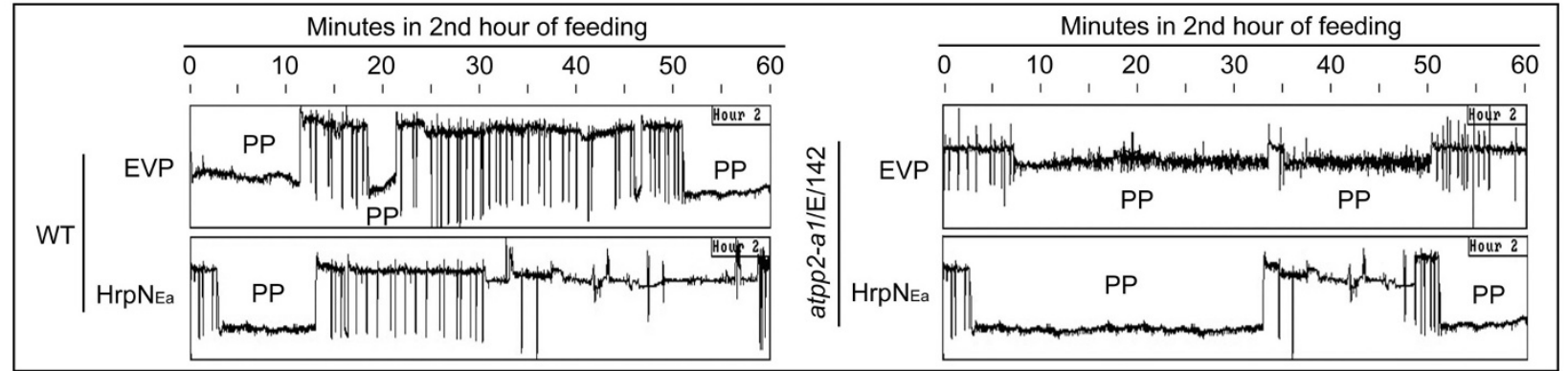

Figure 4 Comparison of Arabidopsis AtPP2-A-modified mutants and WT plant in colonization and phloem feeding by aphids. (a) Changes of aphid population in 24 hours. Plants were treated with $\mathrm{HrpN}_{E a}$ and EVP, respectively. Five days later, uniform aphids were placed on lower sides of the top two expanded leaves (10 aphids/leaf). The number of aphids that stayed in a leaf colony was scored at the 24 th hour after leaf colonization. Percent decrease (mean $\pm S D ; n=120$ leaf colonies) in the number of aphids that run away from the leaf colonies was calculated. (b) Total duration of the phloem phase in a four-hour EPG monitoring course. Plants treated as in (a) were colonized by aphids at the fifth day after treatment; uniform aphids were placed on upper sides of the top first expanded leaves. Feeding activities were detected immediately with a four-channel current amplifier system, and total duration of the phloem phase (mean \pm SD; $n=20$ aphids) was scored. (c) The second-hour EPG record particularly indicating the phloem phase (PP) in WT and an AtPP2-A1-defected mutant. Experiments were the same as in (b). The EPG record represents 20 aphids feeding from 20 plants of WT and the mutant, respectively. (d, e) Reproduction of aphid adults and colonization behaviors of newborn nymphs. Experiments were similar as in (a) and insects were surveyed in five days after colonization of leaves by adults. Reproduction rate was given as the ratio between total number of newborn nymphs and total number of adults on leaf colonies. The population decrease was based on total number of nymphs and the number of nymphs that run away from the leaf colony. Data represent mean $\pm S D(n=120$ leaf colonies).

(Figure 5b). Transformation of the WT plant with the empty pBI121 vector, containing neither uidA nor AtPP2$A 1$, generated the transgenic control plant, which behaved as WT in all the tests (Figure 5b-5d). Also, WT, transgenic control and PP2OETAt plants did not have evident differences in morphology. Homozygous T3 progenies of the PP2OETAt lines were compared the WT and transgenic control plants in AtPP2-A1 expression and in colonization and feeding by apterous $M$. persicae females.

Real-time RT-PCR was conducted with RNA samples from leaves and primers specific to AtPP2-A1. As shown in Figure $5 \mathrm{~b}$, levels of the AtPP2-A1 transcript varied with the different PP2OETAt lines, and levels of the transcript were greater in all the PP2OETAt lines than 
Table 3 Four-hour EPG analysis of aphid feeding from WT Arabidopsis and the atpp2-a1/E/142 mutant

\begin{tabular}{|c|c|c|c|c|c|c|}
\hline \multirow[t]{2}{*}{ Activity examined } & \multicolumn{3}{|c|}{ WT group } & \multicolumn{3}{|c|}{ atpp2-a1/E/142 group } \\
\hline & $\begin{array}{l}\text { EVP treatment } \\
\text { mean }(S D)\end{array}$ & $\begin{array}{l}\mathrm{HrpN}_{\mathrm{Ea}} \text { treatment } \\
\text { mean (SD) }\end{array}$ & $\begin{array}{l}\text { Student's } t \text {-test } \\
\quad(\mathrm{n}=20)\end{array}$ & $\begin{array}{l}\text { EVP treatment } \\
\text { mean }(\mathrm{SD})\end{array}$ & $\begin{array}{c}\mathrm{HrpN}_{\mathrm{Ea}} \\
\text { treatment (SD) }\end{array}$ & $\begin{array}{l}\text { Student's } t \text {-test } \\
\quad(\mathrm{n}=20)\end{array}$ \\
\hline $\begin{array}{l}\text { Total duration of } \\
\text { nonpuncturing, min }\end{array}$ & $21.1(4.8)$ & $18.9(3.5)$ & $p>0.05$ & $31.4(8.3)$ & $28.5(6.4)$ & * \\
\hline $\begin{array}{l}\text { Duration of pathway } \\
\text { phase, min }\end{array}$ & $175.0(50.5)$ & $201.5(58.6)$ & $p<0.05^{*}$ & $160.0(42.0)$ & $162.5(45.5)$ & * \\
\hline $\begin{array}{l}\text { Total duration of phloem } \\
\text { phase, min }\end{array}$ & $43.9(6.3)$ & $19.6(3.9)$ & $p<0.005^{*}$ & $48.6(9.2)$ & $49.0(11.5)$ & * \\
\hline
\end{tabular}

*Insignificant difference at $p<0.05$.

the transgenic control plant. Compared with the transgenic control plant, PP2OETAt lines seemed more resistant to colonization and feeding by aphids. Smaller populations of aphids were able to stay for 24 hours on leaf colonies of PP2OETAt than the transgenic control plant (Figure 5c). Consistently, aphids preferred to feed from the transgenic control plant rather than PP2OETAt (Figure $5 \mathrm{~d}$ ). Total duration of the phloem phase in the four-hour EPG record was much shorter in PP2OETAt than in the control plant (Figure $5 \mathrm{~d}$ ).

Based on statistical analyses (ANOVA test, $p<0.01)$, the ten PP2OETAt lines differed significantly from the transgenic control plant in levels of AtPP2-A1 expression (Figure $5 \mathrm{~b}$ ), the number of aphids that were able to stay for 24 hours on leaf colonies (Figure 5c), and durations of the phloem phase (Figure $5 \mathrm{~d}$ ). In the ten PP2OETAt lines, the number of aphids that were able to stay for 24 hours on leaf colonies was increased (Figure 5c), but durations of the phloem phase was decreased (Figure 5d), with increases in levels of AtPP2$A 1$ expression (Figure $5 \mathrm{~b})$. The PP2OETAt1 line showed as the greatest expresser of $A t P P 2-A 1$ and the greatest repressor of colonization and feeding by $M$. persicae. In addition, a greater repression of phloem feeding by aphids was observed in the presence than the absence of $\mathrm{HrpN}_{\mathrm{Ea}}$ treatment (not shown), suggesting that original and introduced versions of the AtPP2-A1 gene might be able coordinate their functions and might function simultaneously, in PP2OXTA1.

\section{AtPP2-A1 expression in different organs of PP2OETAt1 is consistent with repression of phloem feeding by $M$. \\ persicae}

PP2OETAt1 was further investigated in the genomic integration of the introduced AtPP2-A1 gene, organ specificity of the gene expression, and the effect of $M$. persicae feeding from the phloem. The Southern blot of specifically ingested genomic DNA hybridized with the AtPP2-A1-specific probe revealed that the introduced AtPP2-A1 gene had been integrated into the genome and existed as a double copy in PP2OETAt1 (Figure 6a). Overexpression of the gene was confirmed by northern blot of leaf RNA samples hybridized with the probe specific to AtPP2-A1 (Figure 6b).

Real-time RT-PCR analyses revealed that AtPP2-A1 expression varied greatly in different organs of PP2OETAt1. The expression of AtPP2-A1 was conspicuous in leaves, stems, calyces, and petals but little transcript was detected from flower stalks (Figure 6c). Amounts of the AtPP2-A1 transcript were much greater in leaves, stems, calyces, and petals of PP2OETAt1 than the transgenic control plant. However, close amounts of the transcript were detected from flower stalks of both plants. This result suggested the overexpression of AtPP2-A1 in all the organs except flower stalks of PP2OETAt1. Levels of the gene overexpression were higher in leaves, calyces, and petals compared with stems (Figure 6c; ANOVA test, $p<0.01$ ).

The organ-differential levels of AtPP2-A1 overexpression were negatively correlated with the extents by which apterous agamic $M$. persicae females fed from the different organs. Based on total duration of the phloem phase in the four-hour EPG record (Figure 6d), aphids preferred to feed from leaves, calyces, and petals, but aphids were also able to feed from stems and flower stalks. However, durations of the phloem phase were much shorter when aphids were feeding from leaves, stems, calyces, and petals of PP2OETAt1 compared with the transgenic control plant (Student's $t$-test, $p<0.01$ ), suggesting that the phloem-feeding activity was repressed in the different organs of PP2OETAt1. Inversely, the phloem phase of aphid feeding from the PP2OETAt1 flower stalk lasted as longer as feeding from the same organ of the transgenic control plant (Figure 6d), suggesting that aphids did not have a preference between both plants in feeding from flower stalks.

\section{Expression of AtPP2-A1 promoter-GUS is organ-unspecific}

Because the introduced copies of AtPP2-A1 (Figure 6a) are under direction by $35 S$ (Figure $5 \mathrm{a}$ ), the organ-differential expression in PP2OETAt1 (Figure 6c) does not offer significant information about organ specificity of the gene expression. Lack of the organ specificity was 

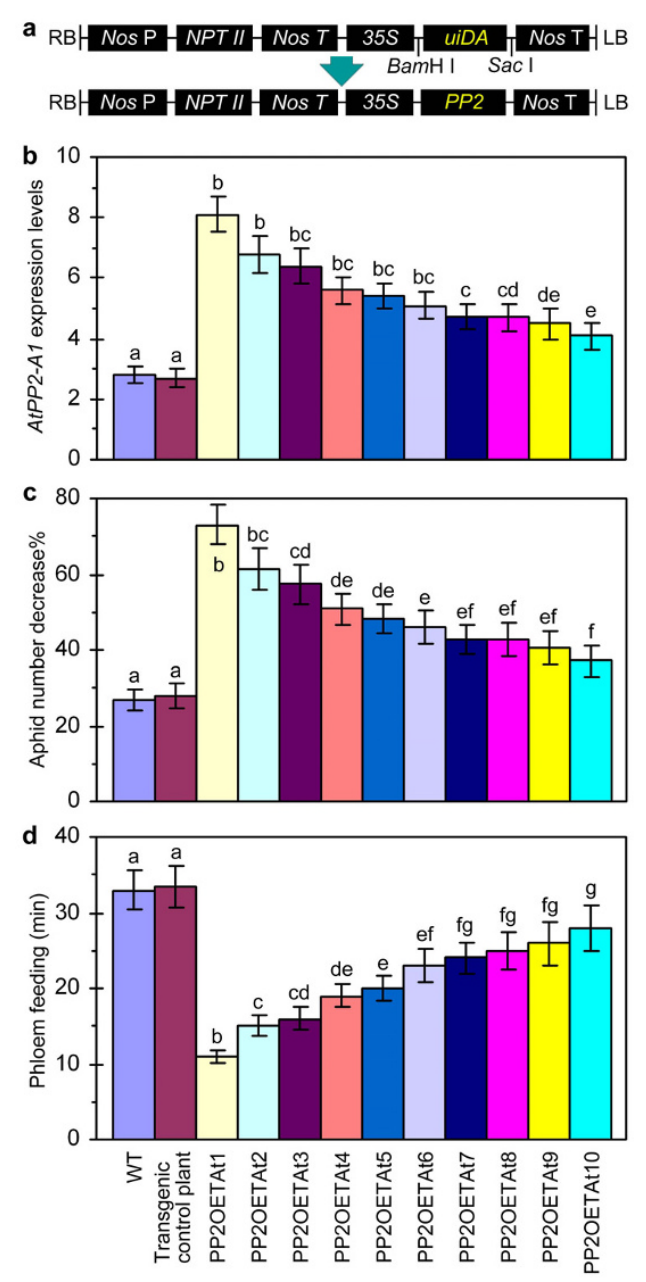

Figure 5 Genetic construction used in generation of PP2OETAt (AtPP2-A1-overexpression transgenic Arabidopsis thaliana) and comparison of PP2OETAt and control plants in AtPP2-A1 expression and aphid activities on leaves. (a) The construct. The AtPP2-A1 (PP2) gene was inserted into the binary vector pBl121 at the $B a m H I$ and $S a c$ I restriction sites to replace uidA, a reporter gene encoding $\beta$-D-glucuronidase. Nos $P$, promoter from the nopaline synthase-encoding gene (Nos); NPT II, kanamycin resistance gene; Nos T, Nos transcription terminator; 35S, the cauliflower mosaic virus 355 promoter. (b-e) Experiments were done with 35day-old plants. Different letter labels in histograms indicate significant differences (ANOVA test, $p<0.01$ ). (b) Real-time RT-PCR analysis of AtPP2-A1 expression in leaves. The gene transcript was quantified as mean $\pm S D$ ( $n=3$ repeats) relative to reference genes (EF1 $\alpha$ and ACTIN2) and normalized to the null-template control. (c) Changes of aphid population in 24 hours. Uniform aphids were placed on lower sides of the top two expanded leaves (10 aphids/ leaf). Leaf colonies were surveyed, the number of aphids that stayed in a leaf colony was scored, and percent decrease (mean $\pm S D ; n=$ 120 leaf colonies) in the number of aphids that run away from the leaf colonies was calculated. (d) Total duration of the phloem phase in a four-hour EPG monitoring course. Uniform aphids were placed on upper sides of the top first expanded leaves. Feeding activities were detected immediately with a four-channel current amplifier system, and total duration of the phloem phase (mean $\pm S D ; n=$ 20 aphids) was scored. a
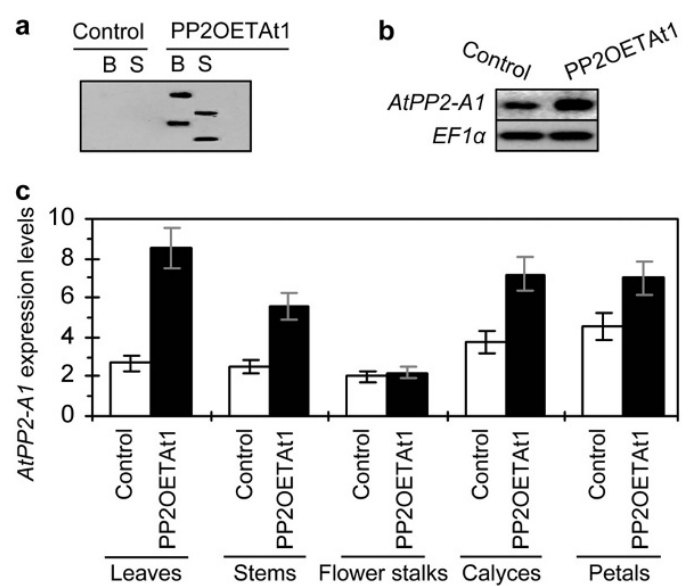

d

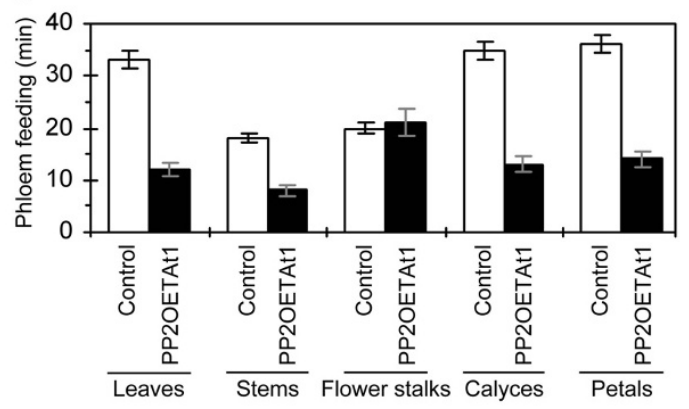

Figure 6 Comparison of PP2OETAt 1 and transgenic control plants in organ-unspecific AtPP2-A1 expression and effects on colonization and phloem feeding by aphids. (a, b) In the experiments, PP2OETAt1 was compared with the transgenic control plant (Control); 35-day-old plants grown in long day were investigated. (a) Southern blot hybridized with the AtPP2-A1-specific probe. Prior to blotting, the genomic DNA had been digested with the restriction enzymes BamH I (B) and Sac I (S). (b) Northern blots hybridized with probes specific to AtPP2-A1 and the reference gene EF1 $\alpha$. (c) Real-time RT-PCR analysis of AtPP2-A1 expression in the different organs of the plants. The gene transcript was quantified as mean \pm SD ( $n=3$ repeats) relative to reference genes and normalized to null-template controls. (d) Total duration of the phloem phase in a four-hour EPG monitoring course. Uniform aphids were placed on the indicated organs. Feeding activities were detected immediately with an EPG monitoring system, and total duration of the phloem phase (mean $\pm S D ; n=20$ aphids) was scored.

indicated by the transcript detected from different organs of the transgenic control plant (Figure 6c). In an experimental design to test whether the organ-unspecific AtPP2-A1 expression was related with activity of the AtPP2-A1 promoter, the promoter placed in front of the uidA reporter gene (Figure $7 \mathrm{a}$ ) was able to drive the gene expression in the uidAETAt (uidA-expressing transgenic $A$. thaliana) plant (Figure 7b). Six uidAETAt lines were observed. They seemed to resemble each other closely and were also similar to the transgenic control plant (Figure 7b; uidAETAt1 as a representative 
line). In the uiDAETAt1 line, uidA was expressed markedly in the stem, flower stalk, calyce, and petal, whereas, stronger expression was found in the leaf (Figure 7c). The uidA gene encodes $\beta$-glucuronidase (GUS) enzyme [43]. GUS activity was detected in the root, stem, calyce, and petal of PP2OETAt1 (Figure 7d). GUS activity was not found in the flower stalk (Figure $7 \mathrm{~d}$ ), possibly due to no uidA expression or little GUS beyond detectable level. In addition, uidAETAt1 showed as tolerant as the transgenic control plant to phloem feeding by M. persicae (Table 4). This result indirectly suggests that AtPP2$A 1$ plays a role, only when expressed itself, in repressing the phloem-feeding activity.

\section{Discussion}

Although harpin proteins and their functions as proteinaceous elicitors in eliciting plant defense responses have been found for decades [1-3], many aspects of the mechanisms that underlie harpin-induced defenses remain unclear. Important questions include, for example, how a harpin protein as an exogenous signal is perceived by plants and how the signal perception is connected to a transducer to trigger a cellular pathway. Great attentions have been paid to plant signal transduction in harpininduced resistance to pathogens $[3,6,30,31,37,44]$ and insect herbivores $[2,4,8,34]$. We have used $\mathrm{HrpN}_{\mathrm{Ea}}$, the first-characterized [1] and well-studied harpin [2-7], as a model of proteinaceous elicitors to characterize induced resistance against insect herbivores [2,4,8,34], particularly the green peach aphid M. persicae, a generalist phloemfeeding insect [10]. It has been shown that the $\mathrm{HrpN}_{\mathrm{Ea}}$ treatment and $M$. persicae infestation have some overlapping effects on the induction of plant responses [4,25,30-34], especially the PBD mechanism that is suggested to involve the lectin-type phloem protein PP2 $[23,24]$ as a component $[14-16,25,26]$. Although 30 members of the PP2 multigene family have been identified in Arabidopsis [23] and AtPP2-modified Arabidopsis mutants generated [27], little is known about biological effects, especially on resistance to insects, of the genes and mutants http://www.arabidopsis.org. The purpose of this study is to elucidate the function of AtPP2-A1 in resistance to $M$. persicae in Arabidopsis plants when treated with $\mathrm{HrpN}_{\mathrm{Ea}}$ and under the condition of AtPP2-A1 overexpression.

We show that the treatment of Arabidopsis with $\mathrm{HrpN}_{\mathrm{Ea}}$ induces a repression in $M$. persicae feeding from the plant phloem (Figure 1; Table 1) and colonization of plants by the insect (Figure 2). Based on the EPG patterns, applying $\mathrm{HrpN}_{\mathrm{Ea}}$ to WT Arabidopsis impedes aphids in stylet puncturing of the plant cell, en route to the vascular tissue while looking for the phloem, and, especially, in the phloem-feeding activity. So the $\mathrm{HrpN}_{\mathrm{Ea}}$ treatment is likely to induce changes in cell wall properties unfavorable to
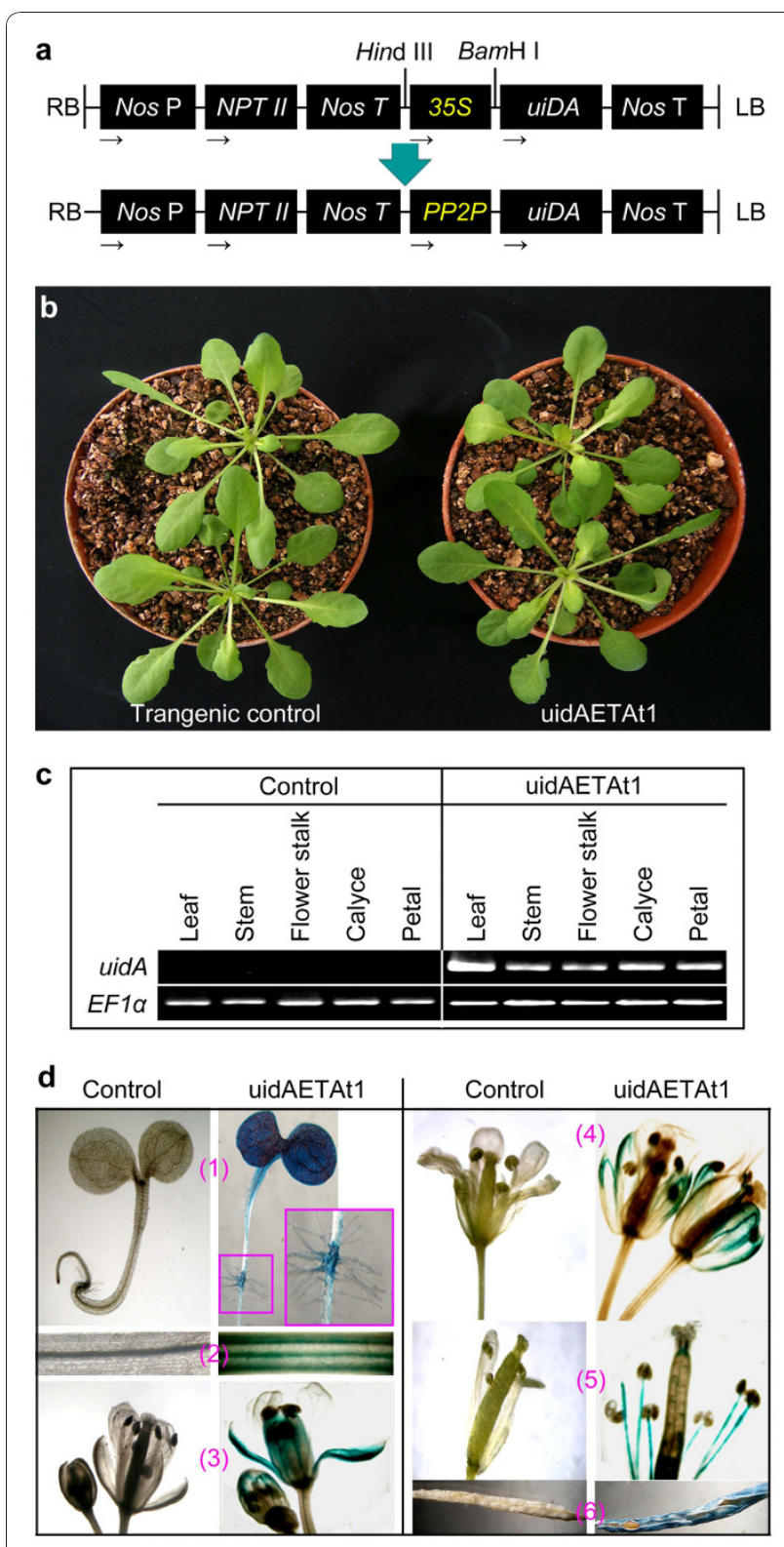

Figure 7 Genetic construction used in generation of uidAETAt (AtPP2-A1-promoter-uidA-expressing A. thaliana) and organunspecific uidA expression in uidAETAt. (a) The construct. The AtPP2-A1 promoter (PP2P) was inserted into the binary vector pBI121 at the Hind III and BamH I restriction sites to replace $35 \mathrm{~S}$ while reserve the reporter gene uidA encoding $\beta$-D-glucuronidase (GUS). Labels are the same as in Figure 5a. (b) Appearance of 35-day-old plants of the uidAETAt1 line compared with the transgenic control plant. (c, d) RT-PCR analysis of uidA expression and GUS activity in different organs of 35-day-old uidAETAt1 compared with the transgenic control plant.

aphid feeding, but this notion remains to be examined. $\mathrm{HrpN}_{\mathrm{Ea}}$-induced deterrent effect on the phloem-feeding activity has been found in the EPG data analyzed either by hour or based on the four-hour record as a whole (Table 1). The phloem-feeding activity could be reflected 
Table 4 Analysis of major activities of aphid feeding from uidAETAt (uidA-expressing transgenic Arabidopsis thaliana) and transgenic control plants

\begin{tabular}{lccc}
\hline Activity examined & Control plant (SD) & uidATEAt1 (SD) & Student's $\boldsymbol{t}$-test (n = 20) \\
\hline Total duration of nonpuncturing, min & $23.5(5.2)$ & $21.9(4.5)$ & $*$ \\
\hline Duration of pathway phase, min & $181.8(56.0)$ & $182.6(61.6)$ & $*$ \\
\hline Total duration of phloem phase, min & $34.7(5.5)$ & $35.5(5.6)$ & $*$ \\
\hline *Insignificant difference at $p<0.05$. & & $*$
\end{tabular}

in the EPG by duration of the phloem phase composed of E1 and E2 salivations (Figure 1), which are essential for ingestion of the phloem sap $[13,16,17,35]$. Shortened duration of the phloem phase, in both E1 and E2 salivations (Table 1), suggests that the insect's effort in ingestion of the phloem sap is repressed under the $\mathrm{HrpN}_{\mathrm{Ea}}$ treatment condition compared with control. It is also pertinent to propose that the $\mathrm{HrpN}_{\mathrm{Ea}}$ treatment impacts the insectplant interaction. In terms of the insect, E1 and E2 saliva are believed to prevent protein clogging inside the sieve element and prevent phloem proteins from clogging inside the capillary food canal $[13,16]$, respectively. In the plant side, phloem protein plugging of the sieve element presumably serves as a physical barrier to aphid feeding from the phloem [26]. The lectin-type phloem protein PP2 $[23,24]$ is supposed to play a role in plant response to the feeding stress $[21,25,26]$.

Molecular and genetic evidence supports a role of Arabidopsis PP2 gene AtPP2-A1 in $\mathrm{HrpN}_{\mathrm{Ea}}$-induced repression of $M$. persicae feeding from the plant phloem. RTPCR analyses (Figure 3 ) suggest that AtPP2-A1 is the most $\mathrm{HrpN}_{\mathrm{Ea}}$-responsive gene of 30 members of the PP2 multigene family [23]. PLACE Web Signal Scan [39] provides a clue to molecular basis of $\mathrm{HrpN}_{\mathrm{Ea}}$ response and the AtPP2-A1 induction as well. For example, the gene promoter contains three copies of the consensus GT-1 binding box GA/GA/TAAA/T (\#S000508) [45]. This element is involved in the regulation of salicylic acid signaling $[45,46]$, which otherwise can be activated by $\mathrm{HrpN}_{\text {Ea }}$ treatment in Arabidopsis [3]. Moreover, previous studies have shown that $\mathrm{HrpN}_{\mathrm{Ea}}$-induced resistance to $M$. persicae is regulated by the ethylene signaling pathway [4], which essentially involves perception of the ethylene signal by the receptor ETR1, the signal transduction to the integral membrane protein EIN2 [4], and the regulation of ethylene responsive factors (ERFs) $[47,48]$. The W-box TGACC/T (\#S000457) present in the AtPP2-A1 promoter has been shown as required for wounding-induced activation of the ERF3 gene [47]. The ERF3 protein is a regulator of ethylene signaling [48], which otherwise is activated to regulate induced resistance to $M$. persicae in Arabidopsis plants responding to $\mathrm{HrpN}_{\mathrm{Ea}}$ treatment [4]. Thus, AtPP2-A1 is pertinently thought a part of the signaling pathway that is required for $\mathrm{HrpN}_{\mathrm{Ea}}$ response, at least during induction of the plant resistance to $M$. persicae [4]. A role of $A t P P 2-A 1$ in the induced resistance has been elucidated by evidence obtained from investigating ten mutants (Table 2) in comparison with the WT plant. The investigation demonstrates that deterrent effect of the $\mathrm{HrpN}_{\mathrm{Ea}}$ treatment on aphid feeding from the phloem requires a functional AtPP2-A1 gene in the plant (Figure 4). This notion is especially supported by the absence of $\mathrm{HrpN}_{\mathrm{Ea}}$-induced repression of the phloemfeeding activity in the atpp2-a1/E/142 mutant (Figure 4; Table 3). This result offers a novel angle to further understanding on the PBD mechanism. Previously, this defensive mechanism was known as a result of plant responses to attacks by phloem-feeding insects $[14,15,20-22]$ and other stresses, such as wounding $[16,21,22,26]$. Now, the PBD mechanism is known to occur as a result of plant response to $\mathrm{HrpN}_{\mathrm{Ea}}$, a proteinaceous elicitor of plant defenses $[1-7,49]$. This notion, however, remains to be examined in regard to how AtPP2-A1 contributes to PBD in response to the $\mathrm{HrpN}_{\mathrm{Ea}}$ treatment.

The function of AtPP2-A1 in conferring repression of the phloem-feeding activity is further supported by evidence obtained from investigating PP2OETAt (AtPP2$A 1$-overexpression transgenic $A$. thaliana) plants (Figure $5)$. Levels of AtPP2-A1 expression are significantly greater in the 10 tested PP2OETAt lines than in the transgenic control plant, conforming to the experimental design for the gene overexpression. In the different PP2OETAt lines, durations of the phloem phase are decreased with increases in levels of AtPP2-A1 expression, suggesting that $A t P P 2-A 1$ overexpression confers a repression in the phloem-feeding activity of $M$. persicae. These observations also identify the PP2OETAt1 line as the greatest expresser of AtPP2-A1 and the greatest repressor of colonization and feeding by the insect. Reminiscently of cell-to-cell PP2 RNA movement in cucurbits [50] and distant phloem transport flowering signals [51], little amount of the AtPP2-A1 transcript in flower stalks (Figure 6) may result from organ-to-organ trafficking to fulfill the requirement for flower development. In the other organs, however, AtPP2-A1 expression is consistent with the repression of aphid feeding from the organs (Figure 6). The organ-unspecific feature of AtPP2-A1 expression and function is also suggested indirectly by investigating the transgenic plant uidAETAt1. In the 
plant, uidA expression under direction of the AtPP2-A1 promoter is found in various organs (Figure 7), but these organs do not have a repressive effect on aphid feeding (Table 4). This result indirectly supported that AtPP2-A1 plays a role, only when expressed itself, in repression of the phloem-feeding activity. Consistent to our observations on uidAETAt1, a previous study detected GUS activity in different organs of transgenic plants that expressed uidA under direction by the AtPP2- $A$ promoter [23]. In the present study, both uidA transcript and GUS activity were detected in different organs of uidAETAt1 (Figure 7). Due to our failure in obtaining transgenic plants that had been designed to express AtPP2$A 1$-uidA under control by the AtPP2-A1 promoter, now we can not provide more convening evidence for coincident organ localization in AtPP2-A1 expression and aphid feeding repression. However, repression of the phloem-feeding activity seems a consistent attribute of the different PP2OETAt lines (Figure 5) and a consistent attribute of the different organs of PP2OETAt1 (Figure 6) as well, owing to AtPP2-A1 overexpression in both cases. In the case of PP2OETAt1, whenever the level of AtPP2-A1 expression is greater in an organ than in the others, aphid feeing from the organ incurs a stronger repression (Figure 6). These observations offer a convincing support for the function of $A t P P 2-A 1$ in conferring the plant resistance shown as a repression in phloemfeeding activity of the insect. The results also indicate a defensive significance of ubiquitous organ-unspecific expression of $P P 2$ genes in plants demonstrated previously [23] and observed in this study (Figure 7).

The contribution of lectin-type phloem proteins, such as PP2, to the PBD mechanism is believed owing to their functions as a physical barrier that prevents insects from phloem feeding [26]. A preceding event is the formation of the PP1-PP2 complex, which, however, has been demonstrated only in cucurbits, whereas, other plant families do not have any PP1-like protein [52]. The role of PP1-PP2 aggregation in the clogging of sieve plates has been the matter of long standing debates that have not yet been solved, and still remains a hypothesis that is beyond elucidating scopes of the present study. Lectin-type phloem proteins take only a small proportion of phloem sap proteins that have potential of defensive significance in plants under attacks by phloem-feeding insects [21]. Thus, lectin-type phloem proteins are only one of different PBD components and are not likely to play an entire role in plant resistance against attacks by the insects [14-21]. Subtle differences in aphid population, the insect escape from leaf colonies, for example, between $\mathrm{HrpN}_{\mathrm{Ea}}$-treated plants and control plants (Figure 2), between atpp2-a1/E/142 and WT (Figure 4), and between PP2OETAt and transgenic control plants
(Figure 5), also imply components alternative to AtPP2-A1 in impacting aphid behaviors while colonizing the plants. Alternative defense components are further indicated by $\mathrm{HrpN}_{\mathrm{Ea}}$-induced impediments to aphid feeding activities observed in the first-hour EPG monitoring (Table 1). However, we do not have evidence yet to show a proportion of AtPP2-A1's contribution to resistance against $M$. persicae in Arabidopsis plants either when treated with $\mathrm{HrpN}_{\mathrm{Ea}}$ or under the condition of AtPP2-A1 overexpression.

Moreover, AtPP2-A1 is a member of the PP2 multigene family [23,27] and atpp2-a1/E/142 is one of AtPP2 mutation alleles in Arabidopsis [24]. The other AtPP2 genes and AtPP2-modified mutants seem not involved in $\mathrm{HrpN}_{\mathrm{Ea}}$-induced repression of aphid feeding from the phloem (Figure 4). This result suggests that different members of the PP2 multigene family may have different functions in the plant. So far, AtPP2-A1 is the only phloem protein demonstrated as a lectin with the ability to bind N-acetylglucosamine oligomers, and recombinant AtPP2-A1 has been shown to affect weight gain in $M$. persicae nymphs in an artificial diet [24]. The induction of $A t P P 2-A 1$ may be an indirect effect of the $\mathrm{HrpN}_{\mathrm{Ea}}$ treatment, which is multifunctional, inducing plant growth enhancement [4], resistance to pathogens [3], insects [4] and drought stress [5], and resistanceassociated cell death $[1,6]$. These multiple effects have been determined separately; and so whether they are simultaneous is unclear. It is also unclear if other PP2 genes affect plant defenses rather than resistance. In several species of angiosperms, including Arabidopsis, different PP2 genes are expressed in various organs during plant growth and development [23]. The ubiquitous organ-unspecific PP2 expression suggests that different PP2 genes may fulfill distinct functions at a special stage of plant growth and development. It is possible that a particular PP2 gene may have different functions depending on plant growth and development processes or depending on an immediate requirement for encountering with distinct challenges, such as attacks by insects and infection by pathogens. Studies to test this hypothesis represent an interesting avenue for further research.

\section{Conclusions}

The $\operatorname{HrpN}_{\mathrm{Ea}}$ treatment has a deterrent effect on the phloem-feeding activity of $M$. persicae and the deterrent effect occurs in WT Arabidopsis rather than the atpp2a1/E/142 mutant. The phloem-feeding activity can be also repressed as a result of AtPP2-A1 overexpression. Both sets of evidence support the conclusion that AtPP2-A1 plays a role in Arabidopsis resistance to the insect, particularly at the phloem-feeding stage. The accompanied change of aphid population in leaf colonies suggests that the function of $A t P P 2-A 1$ is related to 
colonization of the plant and may have a broader importance for the plant-insect interaction.

\section{Methods}

\section{Plant growth and treatment}

Arabidopsis genotypes used in this study included the ecotype Col-0, transgenic plants created in this study, and AtPP2- $A$ sequence-indexed T-DNA insertion lines generated previously (Table 2). Both types of modified plants were created under the background of Col-0 and characterized as homozygous at the transgene and T-DNA insertion loci, respectively, before use in the experiments. Plants were grown in 9 -cm pots, 1 plant/ pot for the EPG monitoring and 5 plants/pot for other experiments, under $22^{\circ} \mathrm{C}$ and $250 \mu \mathrm{E} / \mathrm{m}^{2} / \mathrm{s}$ illumination [53]. A long day (16-h light/8-h dark) photoperiod was applied to plants for transformation and AtPP2-A1 expression in different organs, and short day (with 12-h light/12-h dark) was used in other experiments. Plants grown in short day were used at different stages of growth and development depending on experimental purposes. Transgenic plants were used in different experiments since the 35th day after planting. Thirtyday-old plants of the WT and mutants were treated with EVP and $\mathrm{HrpN}_{\mathrm{Ea}}$, respectively. EVP and $\mathrm{HrpN}_{\mathrm{Ea}}$ were prepared $[1,6]$ as $10 \mu \mathrm{g} / \mathrm{ml}$ aqueous solutions and were applied in the presence of surfactant Silwet-77 $(0.02 \%)$ by spraying plant tops with a low-pressure atomizer. Treated plants were used at $5 \mathrm{dpt}$ in monitoring of aphid behaviors, and were used at 0 and $24 \mathrm{hpt}$ in determination of gene expression.

\section{Aphid culture}

A single isolate of $M$. persicae was collected from the field-grown radish (Raphanus sativus L.) near Nanjing in China. A clone of apterous agamic females was obtained by acclimatization in WT Arabidopsis grown in the chamber $\left(22^{\circ} \mathrm{C} ; 250 \mu \mathrm{E} / \mathrm{m}^{2} / \mathrm{s}\right.$; short day). The colony was maintained in nursery WT Arabidopsis seedlings and was transferred to fresh plants every two weeks. Uniform ten-day-old aphids were used in this study and were transferred to experimental plants with a fine paintbrush.

\section{Aphid feeding behavior}

Aphid feeding activities were observed by the EPG technique using the Giga Amplifier system (Laboratory of Entomology, Wageningen Agricultural University, Wageningen, The Netherlands; http://www.epgsystems.eu/systems.htm). Uniform ten-day-old aphids were placed on upper side of the top first expanded leaves of plants. For each genotype of the plant or each combination of a genotype and treatment (with EVP or $\mathrm{HrpN}_{\mathrm{Ea}}$ ), 20 aphids placed on 20 plants were monitored in five repetitions of experiments. Immediately after aphids were placed on leaves, a $20-\mathrm{mm}$ diameter gold wire was attached to the dorsal surface of each aphid's abdomen using silver conductive paint. The other end of the wire was connected to a four-channel Giga-4 direct current amplifier with four channels and $10^{9}-\Omega$ input resistance in an electrical circuit that is also connected to the plant via an electrode placed in the soil. The behavior of individual aphids was monitored for 4 hours. Voltage waveforms were digitized at 100 $\mathrm{Hz}$ with an A/D converter USB device. Waveform patterns were identified according to previously described categories [35]. Waveform recordings were dissected each 5 second with the EPG analysis software STYLET 2.5 installed in a computer connected to Giga-4 direct current amplifier.

\section{Plant colonization}

Uniform ten-day-old aphids were placed on the lower sides of the top two expanded leaves of plants; 10 aphids per leaf. A total of 1,200 aphids were monitored in four repetitions of the experiments for each single recombination of a treatment and a plant genotype. In each experimental repetition, 300 aphids were placed on 30 leaves of 15 plants treated specifically. Aphid movement from leaf colonies was monitored for five days, and the number of aphids in a leaf colony was scored at intervals in 24 hours. Aphid reproduction was surveyed twice a day, and in each survey, newborn nymphs were counted. Reproduction rate was quantified as the ratio between total numbers of nymphs produced in five days and total numbers of aphid adults that stayed in leaf colonies during the same period. Nymphs produced in five days were also monitored; the number of nymphs that run away from leaf colonies was accounted.

\section{Determination of gene expression in plants}

Total RNA was isolated from leaves of EVP-treated plants and $\mathrm{HrpN}_{\mathrm{Ea}}$-treated WT plants, and was isolated from leaves, stems, flower stalks, calyces, and petals of transgenic plants. Gene expression was determined by northern blot hybridization [31] and RT-PCR or realtime RT-PCR [54] as described previously. Northern blots of leaf RNA samples were hybridized to a digoxigenin-labeled AtPP2-A1 probe prepared using the DIG Nucleic Acid Detection Kit [Roche Diagnostics (Shanghai) Trading Co., LTD]. An established quantitative method [55] was adopted in real-time RT-PCR using $A C T I N 2$ and $E F 1 \alpha$ as reference genes [54,56]. Genes were amplified $<26$ cycles with a range of template concentration increases by $0.5 \mathrm{ng}$ and from 0 to $3.0 \mathrm{ng}$ in $25 \mu \mathrm{l}$ reaction solutions to select desired doses. Reaction treatments, RT-PCR protocols, product cloning and sequencing verification were performed as described $[5,6]$. The $25 \mu \mathrm{l}$ reaction mixture was composed of $1 \mu \mathrm{l}$ 
first-strand cDNA diluted 1:10, $2.5 \mu \mathrm{M}$ primer and $1 \times$ SYBR Premix Ex Taq (TaKaRa Biotech. Co., Ltd, Dalian, China). All reactions were performed in triplicate with null-template controls in which cDNA was absent. PCR cycling was: $95^{\circ} \mathrm{C}$ for $3 \mathrm{~min}$, followed by 40 cycles of $30 \mathrm{sec}$ at $95^{\circ} \mathrm{C}, 30 \mathrm{sec}$ at $60^{\circ} \mathrm{C}$ and $30 \mathrm{sec}$ at $72^{\circ} \mathrm{C}$. Average expression levels of the genes were normalized to the null-template controls. Average level of the AtPP2-A1 transcript was quantified relative to $E F 1 \alpha$ and ACTIN2. The expression of uidA in different organs of the uidATEAt plant was determined by RT-PCR using the superscript II RNAse $\mathrm{H}^{-}$Reverse Transcriptase (Invitrogen Biotech. Shanghai Trading Co., LTD). Primers and related information are provided in Table 5.

\section{Mutant screening}

Information on sequence-indexed T-DNA insertion Arabidopsis mutants tested in this study (Table 2) was from The Arabidopsis Information Resource (TAIR, http:// www.arabidopsis.org) seed stock database. Mutant seeds

Table 5 Information on genes analyzed by reverse transcriptase-polymerase chain reaction in this study

\begin{tabular}{|c|c|c|c|}
\hline Gene & Locus no. & Primers & Product size (bp) \\
\hline$\overline{A C T I N 2}$ & AT3G18780 & $\begin{array}{l}\text { 5'-CCCCTGAGGAGCACCCAGTTCTA-3', } \\
\text { 5'-CATACCCCTCGTAGATTGGCACAG-3' }\end{array}$ & 219 \\
\hline AtPP2-A1 & AT4G19840 & $\begin{array}{l}\text { 5'-GCCTAACGGTAAGGAGAA-3', } \\
5^{\prime}-\text {-TAACTGTTGGGACGAAT-3' }\end{array}$ & 205 \\
\hline AtPP2-A2 & AT4G19850 & $\begin{array}{l}\text { 5'-TCAATTACATGGGCAGAGTCTCAA-3', } \\
\text { 5'-TCTCCACCCACTTGTTCCTTTCTA-3' }\end{array}$ & 401 \\
\hline AtPP2-A3 & AT2G26820 & $\begin{array}{l}\text { 5'-TGTGGTGGACGGAAGGTGCT-3', } \\
\text { 5'-CCTCCTGGCCTACTGTTGATGTAAAA-3' }\end{array}$ & 716 \\
\hline AtPP2-A4 & AT1G33920 & $\begin{array}{l}\text { 5'-GATCTACGCAAGGGATCTTAGCATT-3', } \\
\text { 5'-CTCCAGCATTATCTGGTGATGTCACGAACT-3' }\end{array}$ & 371 \\
\hline AtPP2-A5 & AT1G65390 & $\begin{array}{l}\text { 5'-GTAAAGTCAATCGTCAAGGCTGTTAA-3', } \\
\text { 5'-TTCTCCCAAGTATTCGGCAAGTC-3' }\end{array}$ & 524 \\
\hline AtPP2-A6 & AT5G45080 & $\begin{array}{l}\text { 5'-ATGGCTTCTTCTTCCTCGGTTGTG-3, } \\
\text { 5'-GAGTTGGTGCCTCGTTGATGGT-3' }\end{array}$ & 797 \\
\hline AtPP2-A7 & AT5G45090 & $\begin{array}{l}\text { 5'-TAATGAATCCGCCGATGAAGC-3', } \\
\text { 5'-CAACACCTITGACCACGAGCC-3' }\end{array}$ & 638 \\
\hline AtPP2-A8 & AT5G45070 & $\begin{array}{l}\text { 5'-AATGCGATTCCCATCTTCTACAAAC-3', } \\
\text { 5'-CACTCATAACCACCTTCAGCGTCA-3' }\end{array}$ & 565 \\
\hline AtPP2-A9 & AT1G31200 & $\begin{array}{l}\text { 5'-GTTCGCATCATAAGGCAGACTCCA-3', } \\
\text { 5'-TTCTTGAACAAAGGCTTCGTGGA-3' }\end{array}$ & 521 \\
\hline AtPP2-A10 & AT1G10150 & $\begin{array}{l}\text { 5'-AATCCCTAACAGCTTGAAGCAGATC-3', } \\
\text { 5'-TGCAATAGCCTCAGTCCACCC-3' }\end{array}$ & 694 \\
\hline AtPP2-A11 & AT1G63090 & $\begin{array}{l}\text { 5'-CGCTTCTTGGGCTGATTTCG-3', } \\
\text { 5'-GACTCCAGTTICCTGCTTCGGTTA-3' }\end{array}$ & 533 \\
\hline AtPP2-A12 & AT1G12710 & $\begin{array}{l}\text { 5'-TTGTCTTCTTCATCTTGTTTTGGGG-3', } \\
\text { 5'-CCGCTTCAACTGGTCTTTACACGAG-3' }\end{array}$ & 837 \\
\hline AtPP2-A13 & AT3G61060 & $\begin{array}{l}\text { 5'-CAGATTGGTGGATTACCTGAGAATT-3', } \\
\text { 5'-TTGTTGGTTGTCCGAAGTGGC-3' }\end{array}$ & 598 \\
\hline AtPP2-A14 & AT5G52120 & $\begin{array}{l}\text { 5'AGACAAACTTATTTACCGC-3', } \\
\text { 5'-AACTGCTTCTAACCACCAT-3' }\end{array}$ & 244 \\
\hline AtPP2-A15 & AT3G53000 & $\begin{array}{l}\text { 5'-TTTCGTGGTGCGGCTTCTTC-3', } \\
\text { 5'-TGCGTGCAGTCAATCTGTTTCAT-3' }\end{array}$ & 659 \\
\hline AtPP2-B1 & AT2G02230 & $\begin{array}{l}\text { 5'-CGAGTCCTCGGGACGCTTGT-3', } \\
\text { 5'-CCACGGACGCCTCATCCTAAA-3' }\end{array}$ & 620 \\
\hline AtPP2-B2 & AT2G02250 & $\begin{array}{l}\text { 5'-CCGGTTCTTCGTCGATGGTG-3', } \\
\text { 5'-AAGCCGAGTAACGGGTTCCAG-3' }\end{array}$ & 537 \\
\hline AtPP2-B3 & AT2G02270 & $\begin{array}{l}\text { 5'-TTTGCTGCTTCGGTTTCG-3', } \\
\text { 5'-CCCATGAGATCACCATTCCCT-3' }\end{array}$ & 792 \\
\hline AtPP2-B4 & AT2G02280 & $\begin{array}{l}\text { 5'-ATGAATACTCAAATCCTATC-3', } \\
\text { 5'-TTATGGGCTITTCGTAGGGCGGATA-3' }\end{array}$ & 435 \\
\hline AtPP2-B5 & AT2G02300 & $\begin{array}{l}\text { 5'-GTTCCTTGCTGCTTTGGTTTCG-3', } \\
\text { 5'-CCATCCACCCATCTTGCCTCT-3' }\end{array}$ & 536 \\
\hline
\end{tabular}


Table 5 Information on genes analyzed by reverse transcriptase-polymerase chain reaction in this study (Continued)

\begin{tabular}{|c|c|c|c|}
\hline AtPP2-B6 & AT2G02310 & $\begin{array}{l}\text { 5'-TGGAATCTATCGGTGGAGGCG-3', } \\
\text { 5'-CAACTTGTATAGGCAAATCTCGTAAGC-3' }\end{array}$ & 570 \\
\hline AtPP2-B7 & AT2G02320 & $\begin{array}{l}\text { 5'-AGCCGTTGTCTITGGGTGATT-3', } \\
\text { 5'-ACGTTCGTATTGCGCTGAGTAG-3' }\end{array}$ & 755 \\
\hline AtPP2-B8 & AT2G02340 & $\begin{array}{l}\text { 5'-TCACAAGCCCTCAAGATGCG-3', } \\
\text { 5'-CACCACTCCAACTACAACTTCTACGG-3' }\end{array}$ & 498 \\
\hline AtPP2-B9 & AT2G02350 & $\begin{array}{l}\text { 5'-TGCAACTGCGATGAATCTATCAAG-3', } \\
\text { 5'-CTGCTGGGCGTATTTACCCTCT-3' }\end{array}$ & 448 \\
\hline AtPP2-B10 & AT2G02360 & $\begin{array}{l}\text { 5'-GCGTCGCTGCTACGGTTTCG-3', } \\
\text { 5'-GCTCAATCTCCATCCACCCATCTT-3' }\end{array}$ & 579 \\
\hline AtPP2-B11 & AT1G80110 & $\begin{array}{l}\text { 5'-TGCGGCACCTGCTGGTCTTC-3', } \\
\text { 5'-CCCTTTGTCTCCTTGAGGCTCATCTC-3' }\end{array}$ & 558 \\
\hline AtPP2-B12 & AT5G24560 & $\begin{array}{l}\text { 5'-GCGGCGGATTCCAATACCA-3', } \\
\text { 5'-AAGTTCAATCTCCAACCACCCATC-3' }\end{array}$ & 525 \\
\hline AtPP2-B13 & AT1G56240 & $\begin{array}{l}\text { 5'-CCAACATCCTTGCCTTCACATC-3', } \\
\text { 5'-TCTCCAACCACCCGTCGTCT-3' }\end{array}$ & 690 \\
\hline AtPP2-B14 & AT1G56250 & $\begin{array}{l}\text { 5'-ATAGCCAACATCCTTGCCTTCA-3', } \\
\text { 5'-TCAATCTCCATCCATCCGTCAT-3' }\end{array}$ & 698 \\
\hline AtPP2-B15 & AT1G09155 & $\begin{array}{l}\text { 5'-ATCTCGTCGGCGGCTGTCTC-3', } \\
\text { 5'-CTATCTCCATCCACCCATCGTCTC-3' }\end{array}$ & 649 \\
\hline$E F 1 \alpha$ & AT1G07930 & $\begin{array}{l}\text { 5'-CCCCTTCGTCTCCCACTTCAGGATGTCTA-3', } \\
\text { 5'-GTTGTCACCTGGAAGTGCCTCAAGAAG-3' }\end{array}$ & 189 \\
\hline$\overline{K^{\prime} n^{r}}$ & HM047294 & $\begin{array}{l}\text { 5'-GGCTATGACTGGGCACAACAGACAA-3', } \\
\text { 5'-GCGGCGATACCGTAAAGCACGAGGA-3' }\end{array}$ & 683 \\
\hline uidA & U00096 & $\begin{array}{l}\text { 5'-GGGGTGGCAGTGAAGGGCGAACAGT-3', } \\
\text { 5'-TGGGAGAACATTAGGTAGACGCAGGTGA-3' }\end{array}$ & 533 \\
\hline
\end{tabular}

were provided as either homologous (atpp2-a1/P/-210, atpp2-a10/P/-157, and atpp2-a3/I/1650) or heterozygous (the other seven mutants) at the insertion loci (Table 2). Homozygous progenies of heterozygous mutants were obtained by a PCR-based screening protocol according to information shown in Table 2. Provided mutant seeds were used to grow progeny plant lines and new seeds were harvested separately from five lines of each mutant. In the next generation, five lines of a mutant were grown for use to analyze the T-DNA insert and identify homozygous plants. Genomic DNA was isolated separately from ten plant individuals of each line and subjected to PCR analyses with $\mathrm{Kan}^{r}$-specific primers (Table 5). Seeds from the line that had $\mathrm{Kan}^{r}$ in all the ten plant individuals were regarded as homozygous at the insertion locus.

\section{Promoter analyses}

Promoter sequences of the AtPP2-A genes (Figure $3 \mathrm{~b}$ ) were predicted with the AtcisDB program http://arabidopsis.med.ohio-state.edu/. Presence and locations of plant cis-acting regulatory DNA elements in the promoter sequences were determined by analyses with the PLACE Web Signal Scan program http://www.dna.affrc. go.jp/PLACE/signalup.html [39]. The cis-acting regulatory DNA elements were correlated with genes and processes by browsing linked web information and publications.
Generation and characterization of transgenic plants The binary vector pBI121 (EMD Bioscience Inc., Gibbstown, NJ, USA), which contains the NPT II gene encoding kanamycin resistance, $35 S$ and $u i d A$, was used to construct transformation units. Full length cDNA of the AtPP2 gene used in construction of pBI121::35S::AtPP2-A1 was obtained by RT-PCR conducted with RNA isolate from leaves of $\mathrm{HrpN}_{\mathrm{Ea}}$-treated plants and AtPP2-A1-specific primers (5'-CGGGATCCATGAGCAAGAAACATTGCTCAG-3' and 5' -CGAGCTCTTACTGTTTGGGACGA ATTGCAACAC-3'; underline indicates protection bases; italics indicate $\mathrm{BamH}$ I and $\mathrm{Sac}$ I restriction bases). The gene was inserted into the pBI121 vector at the $B a m \mathrm{H}$ I and $S a c$ I restriction sites to replace uidA (Figure 5a). The AtPP2-A1 promoter was obtained by PCR using the genomic DNA from WT plant and the specific primers (5'CCCAAGCTTGATAATTTTTCAAGACCC-3' and 5'CGGGATCCAAACCAGTATGATGTATT-3'; underline indicates protection bases; italics indicate Hind III and $B a m H$ I restriction bases). The promoter sequence was inserted pBI121 at the Hind III and BamH I restriction sites to replace $35 S$ (Figure $7 \mathrm{a}$ ), creating pBI121::PP2P:: uidA.

Recombinant vector was transferred into cells of Agrobacterium tumefaciems strain EHA105. A suspension of EHA105 cells containing the empty pBI121 vector (without $A t P P 2-A 1$ and uidA inserts) or the recombinant 
vector were used to transform WT Arabidopsis by blossom infiltration. Transformation with pBI121::GUS:: AtPP2-A1 and pBI121::PP2P::uidA generated PP2OETAt and uidAETAt plants, respectively. Both types of transgenic plants were screened, multiplied and characterized by a previously described protocol [31]. The phenotype of kanamycin resistance was used in screening of PP2OETAt candidates and the transgenic control plant candidates, respectively; the phenotype of both kanamycin resistance and GUS activity was used in screening of uidAETAt candidates. GUS activity was determined using the histochemical techniques described previously [57]. Screened transgenic plants were allowed to selfpollinate and selected to the T3 generation [58]. T3 homozygous progenies were used in this study. The genomic integration of the transgene in PP2OETAt was detected by Southern blot analysis [54]. For Southern blots, Arabidopsis genomic DNA was digested with BamH I and Sac I, and transferred to a nylon membrane, followed by hybridization to a digoxigenin-labeled AtPP2-A1 probe prepared using the DIG Nucleic Acid Detection Kit [Roche Diagnostics (Shanghai) Trading Co., LTD].

\section{Data treatment}

Experiments were done three or four times with similar results. The student's $t$-test was used to compare data obtained from $\mathrm{HrpN}_{\mathrm{Ea}}$-treated plants with those obtained from EVP-treated plants, and to compare data obtained from the transgenic control plant with those obtained from each line of PP2OETAt. Quantitative data were also analyzed by the ANOVA test to compare differences among the transgenic control plant and different lines of PP2OETAt, and among different organs of transgenic plants.

\section{Acknowledgements}

We thank the two anonymous reviewers for comments on the manuscript and scrutiny on characters of the mutants, our colleagues Miss Qiuxia Wang and Dr. Shuwen Wu for assistance in the EPG technique and insect nursery maintenance, and all the students in the lab for assistance in insect survey. This study was supported by grants from China National Novel Transgenic Organisms Breeding Project (2009ZX08002-004B and 2008ZX08002-001) and National Science Foundation of China (30771441).

\section{Author details \\ 'Key Laboratory of Monitoring and Management of Crop Pathogens and Insect Pests, Ministry of Agriculture of R. P. China, Nanjing Agricultural University, Nanjing, 210095, PR China. ${ }^{2}$ Institute of Utilization of Nuclear Techniques, Zhejiang Academy of Agricultural Sciences, Hangzhou, 310021, PR China.}

\section{Authors' contributions}

$C Z, X W$ and SZ carried out EPG studies, investigated insect population, and performed the statistical analysis. CZ and LC also participated in the design of the study and drafted the manuscript. HS and BL did bioinformatics analyses and determined gene expression. HS also investigated aphid nymphs. XW, LY and RL generated and characterized transgenic plants. BL,
$J Q$, WS and ZY participated in the insect monitoring experiments. HD conceived of the study, and participated in its design and coordination and helped to draft the manuscript. All authors read and approved the final manuscript.

Received: 20 August 2010 Accepted: 13 January 2011

Published: 13 January 2011

\section{References}

1. Wei ZM, Laby RJ, Zumoff CH, Bauer DW, He SY, Collmer A, Beer SV: Harpin, elicitor of the hypersensitive response produced by the plant pathogen Erwinia amylovora. Science 1992, 257:85-88.

2. Kim JF, Beer SV: hrp genes and harpins of Erwinia amylovora: a decade of discovery. In Fire blight and its causative agent, Erwinia amylovora. Edited by: Vanneste JL. C.A.B. International, Wallingford, U.K; 2000:141-162.

3. Dong H, Delaney TP, Bauer DW, Beer SV: Harpin induces disease resistance in Arabidopsis through the systemic acquired resistance pathway mediated by salicylic acid and the NIM1 gene. Plant J 1999, 20:207-215.

4. Dong HP, Peng J, Bao Z, Meng X, Bonasera JM, Chen G, Beer SV, Dong H: Downstream divergence of the ethylene signaling pathway for harpinstimulated Arabidopsis growth and insect defense. Plant Physio/ 2004, 136:3628-3638

5. Dong HP, Yu H, Bao Z, Guo X, Peng J, Yao Z, Chen G, Dong H: The ABI2dependent abscisic acid signalling controls $\mathrm{HrpN}$-induced drought tolerance in Arabidopsis. Planta 2005, 221:313-327.

6. Peng J, Dong H, Dong HP, Delaney TP, Bonasera BM, Beer SV: Harpinelicited hypersensitive cell death and pathogen resistance requires the NDR1 and EDS1 genes. Physiol Mol Plant Pathol 2003, 62:317-326.

7. Ren X, Liu F, Bao Z, Zhang C, Wu X, Chen L, Liu R, Dong H: Root growth of Arabidopsis thaliana is regulated by ethylene and abscisic acid signaling interaction in response to $\mathrm{HrpN}_{\mathrm{Ea}}$ a bacterial protein of harpin group. Plant Mol Biol Rep 2008, 26:225-240.

8. Zitter TA, Beer SV: Harpin for insect control. Phytopathology 1998, 88: S104-S105.

9. Gou Z, Zhang S, Dong H: Effects of $\mathrm{HrpN}_{\mathrm{Ea}}$ on inducing aphid repellency on Cucumis melo. Acta Agric Boreali-Sinica 2009, 24:188-192.

10. Pollard DG: Plant penetration by feeding aphids (Hemiptera, Aphidoidea): A review. Bul Entomol Res 1972, 62:631-714.

11. Douglas AE: Phloem-sap feeding by animals: problems and solutions. $J$ Exp Bot 2006, 57:747-754.

12. Kempema LA, Cui $X$, Holzer FM, Walling LL: Arabidopsis transcriptome changes in response to phloem-feeding silver leaf whitefly nymphs. Similarities and distinctions in responses to aphids. Plant Physiol 2007 143:849-865.

13. Mutti NS, Louis J, Pappan LK, Pappan K, Begum K, Chen M, Park Y, Dittmer N, Marshall J, Reese JC, Reeck GR: A protein from the salivary glands of the pea aphid, Acyrthosiphon pisum, is essential in feeding on a host plant. Proc Nat Acad Sci USA 2008, 105:9965-9969.

14. De Vos M, Jander G: Myzus persicae (green peach aphid) salivary components induce defence responses in Arabidopsis thaliana. Plant Cell Environ 2009, 32:1548-1560.

15. Will T, van Bel AJ: Induction as well as suppression: How aphid saliva may exert opposite effects on plant defense. Plant Signal Behav 2008, 3:427-430

16. Tjallingii WF: Salivary secretions by aphids interacting with proteins of phloem wound responses. J Exp Bot 2006, 57:739-745.

17. Klingler J, Creasy R, Gao L, Nair RM, Calix AS, Jacob HS, Edwards OR, Singh KB: Aphid resistance in Medicago trunculata involves antixenosis and phloem-specific, inducible antibiosis, and maps to a single locus flanked by NBS-LRR resistance gene analogs. Plant Physiol 2005, 137:1445-1455.

18. Pegadaraju V, Louis J, Singh V, Reese JC, Bautor J, Feys BJ, Cook G, Parker JE, Shah J: Phloem-based resistance to green peach aphid is controlled by Arabidopsis PHYTOALEXIN DEFICIENT4 without its signaling partner ENHANCED DISEASE SUSCEPTIBILITY1. Plant J 2007, 52:332-341.

19. Louis J, Leung Q, Pegadaraju V, Reese J, Shah J: PAD4-dependent antibiosis contributes to the ssi2-conferred hyper-resistance to the green peach aphid. Mol Plant-Microbe Interact 2010, 23:618-627.

20. Stone BA, Clarke AE: Chemistry and physiology of higher plant 1,3- $\beta$ glucans (callose). In Chemistry and biology of 1,3- $\beta$-glucans. Edited by: Stone BA, Clarke AE. Bundoora Australia: La Trobe University Press; 1992:365-429. 
21. Kehr J: Phloem sap proteins: their identities and potential roles in the interaction between plants and phloem-feeding insects. J Exp Bot 2006, 57:767-774.

22. Willats WGT, Knox JP: Molecules in context: probes for cell wall analysis. In The Plant Cell Wall. Edited by: Rose JKC. Oxford UK: CRC Press; 2003:92-110.

23. Dinant S, Clark AM, Zhu Y, Vilaine F, Palauqui JC, Kusiak C, Thompson GA: Diversity of the superfamily of phloem lectins (phloem protein 2) in angiosperms. Plant Physiol 2003, 131:114-128.

24. Beneteau J, Renard D, Marche L, Douville E, Lavenant L, Rahbe Y, Dupont D, Vilaine $\mathrm{F}$, Dinant S: Binding properties of the $\mathrm{N}$-acetylglucosamine and high-mannose N-glycan PP2-A1 phloem lectin in Arabidopsis. Plant Physiol 2010, 153:1345-1361.

25. Read SM, Northcote DH: Subunit structure and interactions of the phloem proteins of Cucurbita maxima (pumpkin). Eur J Biochem 1983, 134:561-569.

26. Will T, van Bel AJE: Physical and chemical interactions between aphids and plants. J Exp Bot 2006, 57:729-737.

27. Alonso JM, Stepanova AN, Leisse TJ, Kim CJ, Chen H, Shinn P, Stevenson DK, Zimmerman J, Barajas P, Cheuk R, et al: Genome-wide insertional mutagenesis of Arabidopsis thaliana. Science 2003, 301:653-657

28. McElver J, Tzafrir I, Aux G, Rogers R, Ashby C, Smith K, Thomas C, Schetter A, Zhou Q, Cushman MA, et al: Insertional mutagenesis of genes required for seed development in Arabidopsis thaliana. Genetics 2001, 159:1751-1763.

29. Divol F, Vilaine F, Thibivilliers S, Kusiak C, Helene Sauge M, Dinant S: Involvement of the xyloglucan endotransglycosylase/hydrolases encoded by celery XTH1 and Arabidopsis XTH33 in the phloem response to aphids. Plant Cell and Environ 2007, 30:187-201.

30. Liu F, Liu H, Jia Q, Wu X, Guo X, Zhang S, Song F, Dong H: The internal glycine-rich motif and cysteine suppress several effects of the $\mathrm{HpaG}_{\text {Xooc }}$ protein in plants. Phytopathology 2006, 96:1052-1059.

31. Peng J, Bao Z, Dong $H$, Ren $H$, Wang J: Expression of harpin Xoo $_{\text {in }}$ transgenic tobacco induces pathogen defense in the absence of hypersensitive cell death. Phytopathology 2004, 94:1048-1055.

32. De Vos M, Van Oosten VR, Van Poecke RMP, Van Pelt JA, Pozo MJ, Mueller MJ, Buchala AJ, Métraux JP, Van Loon LC, Dicke M, Pieterse CMJ: Signal signature and transcriptome changes of Arabidopsis during pathogen and insect attack. Mol Plant-Microbe Interact 2005, 18:923-927.

33. Thompson GA, Goggin FL: Transcriptomics and functional genomics of plant defence induction by phloem-feeding insects. J Exp Bot 2006, 57:755-766.

34. Liu R, Lü B, Wang X, Zhang C, Zhang S, Qian J, Chen L, Shi H, Dong H: Thirty-seven transcription factor genes differentially respond to a harpin protein and affect resistance to the green peach aphid in Arabidopsis. J Biosci 2010, 35:435-450.

35. Tjallingii WF, Esch TH: Fine-structure of aphid stylet routes in plant tissues in correlation with EPG signals. Physiol Entomol 1993, 18:317-328.

36. Tjallingii WF: Electrical recording of stylet penetration activities. In Aphids: Their Biology, Natural Enemies and Control. Volume 2B. Edited by: Minks AK, Harrewijn P. Elsevier Amsterdam; 1987:95-108.

37. Chen L, Qian J, Qu S, Long J, Yin Q, Zhang L, Wu X, Sun F, Wu T, Hayes M, Beer SV, Dong H: Identification of specific fragments of $\mathrm{HpaG}_{\mathrm{Xooc}}$ a harpin from Xanthomonas oryzae pv. oryzicola, that induce disease resistance and enhance growth in plants. Phytopathology 2008, 98:781-791.

38. Sun L, Ren H, Liu R, Li B, Wu T, Sun F, Liu H, Wang X, Dong H: An h-type thioredoxin functions in tobacco defense responses to two species of viruses and an abiotic oxidative stress. Mol Plant-Microbe Interact 2010, 23:1470-1485.

39. Higo $K$, Ugawa $Y$, Iwamoto $M$, Korenaga T: Plant cis-acting regulatory DNA elements (PLACE) database: 1999. Nucleic Acids Res 1999, 27:297-300.

40. Bate N, Twell D: Functional architecture of a late pollen promoter: pollen-specific transcription is developmentally regulated by multiple stage-specific and co-dependent activator elements. Plant Mol Biol 1998, 37:859-869

41. Filichkin SA, Leonard JM, Monteros A, Liu PP, Nonogaki H: A novel endo- $\beta$ mannanase gene in tomato LeMAN5 is associated with anther and pollen development. Plant Physiol 2004, 134:1080-1087.
42. Abe H, Urao T, Ito T, Seki M, Shinozaki K, Yamaguchi-Shinozaki K: Arabidopsis AtMYC2 (bHLH) and AtMYB2 (MYB) function as transcriptional activators in abscisic acid signaling. Plant Cell 2003, 15:63-78.

43. Jefferson RA, Burgess SM, Hirsh D: $\beta$-Glucuronidase from Escherichia coli as a gene-fusion marker. Proc Natl Acad Sci USA 1986, 83:8447-8451.

44. Miao WG, Wang XB, Li M, Song CF, Wang Y, Hu DW, Wang JS: Genetic transformation of cotton with a harpin-encoding gene $h p a_{X o o}$ confers an enhanced defense response against different pathogens through a priming mechanism. BMC Plant Biol 2010, 10:67.

45. Buchel AS, Brederode FT, Bol JF, Linthorst HJM: Mutation of GT-1 binding sites in the Pr-1A promoter influences the level of inducible gene expression in vivo.. Plant Mol Biol 1999, 40:387-396.

46. Yu D, Chen $C$, Chen Z: Evidence for an important role of WRKY DNA binding proteins in the regulation of NPR1 gene expression. Plant Cell 2001, 13:1527-1540.

47. Nishiuchi $T$, Shinshi $H$, Suzuki K: Rapid and transient activation of transcription of the ERF3 gene by wounding in tobacco leaves: Possible involvement of NtWRKYs and autorepression. J Biol Chem 2004, 279:55355-55361.

48. Fujimoto SY, Ohta M, Usui A, Shinshi H, Ohme-Takagi M: Arabidopsis ethylene-responsive element binding factors act as transcriptional activators or repressors of GCC box-mediated gene expression. Plant Cell 2000, 12:393-404.

49. Zhang C, Bao Z, Liang Y, Yang X, Wu X, Hong X, Dong H: Abscisic acid mediates Arabidopsis drought tolerance induced by $\mathrm{HrpN}_{\mathrm{Ea}}$ in the absence of ethylene signaling. Plant Mol Biol Rep 2007, 25:98-114.

50. Balachandran S, Xiang Y, Schobert C, Thompson GA, Lucas WJ: Phloem sap proteins from Cucurbita maxima and Ricinus communis have the capacity to traffic cell to cell through plasmodesmata. Proc Natl Acad Sci USA 1997, 94:14150-14155.

51. Giakountis A, Coupland G: Phloem transport of flowering signals. Curr Opin Plant Biol 2008, 11:687-694.

52. Clark AM, Jacobsen KR, Bostwick DE, Dannenhoffer JM, Skaggs MI, Thompson GA: Molecular characterization of a phloem-specific gene encoding the filament protein, phloem protein 1 (PP1), from Cucurbita maxima. Plant J 1997, 12:49-61.

53. Zhang S, Yang $X$, Sun M, Sun F, Deng S, Dong H: Riboflavin-induced priming for pathogen defense in Arabidopsis thaliana. J Integr Plant Biol 2009, 51:167-174.

54. Wu T, Guo A, Zhao Y, Wang X, Wang Y, Zhao D, Li X, Ren H, Dong H: Ectopic expression of the rice lumazine synthase gene contributes to defense responses in transgenic tobacco. Phytopathology 2010, 100:573-581

55. Livak KJ, Schmittgen TD: Analysis of relative gene expression data using real-time quantitative PCR and the $2^{-\Delta \Delta C T}$ method. Methods 2001, 25:402-408.

56. Volkov RA, Panchuk II, Schöffl F: Heat-stress-dependency and developmental modulation of gene expression: the potential of housekeeping genes as internal standards in mRNA expression profiling using real-time RT-PCR. J Exp Bot 2003, 54:2343-2349.

57. Jefferson RA, Kavanagh TA, Bevan MW: GUS fusions: $\beta$-glucuronidase as a sensitive and versatile gene fusion marker in higher plants. EMBO J 1987, 6:3901-3907.

58. Weigle D, Glazebrook J: Arabidopsis: a Laboratory Manual. Cold Spring New York: Cold Harbor Laboratory Press; 2002.

doi:10.1186/1471-2229-11-11

Cite this article as: Zhang et al.: Harpin-induced expression and transgenic overexpression of the phloem protein gene AtPP2-A1 in Arabidopsis repress phloem feeding of the green peach aphid Myzus persicae. BMC Plant Biology 2011 11:11. 